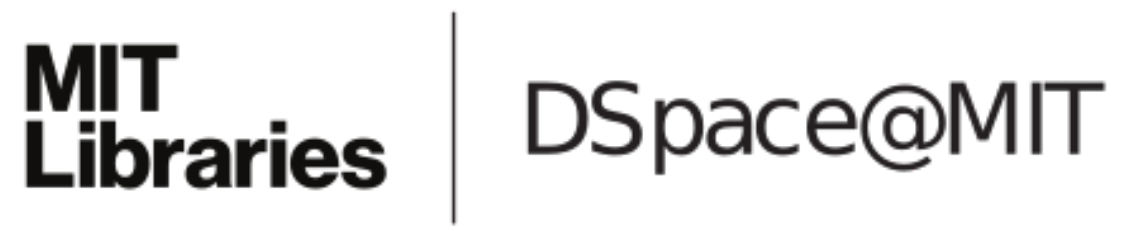

\author{
MIT Open Access Articles
}

Chemomechanics of ionically conductive ceramics for electrical energy conversion and storage

The MIT Faculty has made this article openly available. Please share how this access benefits you. Your story matters.

Citation: Swallow, J. G., W. H. Woodford, Y. Chen, Q. Lu, J. J. Kim, D. Chen, Y.-M. Chiang, et al. "Chemomechanics of Ionically Conductive Ceramics for Electrical Energy Conversion and Storage." Journal of Electroceramics 32, no. 1 (January 16, 2014): 3-27.

As Published: http://dx.doi.org/10.1007/s10832-013-9872-2

Publisher: Springer Science+Business Media

Persistent URL: http://hdl.handle.net/1721.1/91617

Version: Author's final manuscript: final author's manuscript post peer review, without publisher's formatting or copy editing

Terms of use: Creative Commons Attribution-Noncommercial-Share Alike 


\section{Chemomechanics of ionically conductive ceramics for electrical energy conversion and storage}

\author{
J. G. Swallow • W. H. Woodford • Y. Chen • Q. Lu • \\ J. J. Kim • D. Chen · Y.-M. Chiang • W. C. Carter • \\ B. Yildiz $\cdot$ H. L. Tuller $\cdot$ K. J. Van Vliet
}

Received: 3 May 2013 / Accepted: 22 October 2013

(C) Springer Science+Business Media New York 2014

\begin{abstract}
Functional materials for energy conversion and storage exhibit strong coupling between electrochemistry and mechanics. For example, ceramics developed as electrodes for both solid oxide fuel cells and batteries exhibit cyclic volumetric expansion upon reversible ion transport. Such chemomechanical coupling is typically far from thermodynamic equilibrium, and thus is challenging to quantify experimentally and computationally. In situ measurements and atomistic simulations are under rapid development to explore how this coupling can be used to potentially improve both device performance and durability. Here, we review the commonalities of coupling between electrochemical and mechanical states in fuel cell and battery materials, illustrating with specific cases the progress in materials processing, in situ characterization, and computational modeling and simulation. We also highlight outstanding questions and opportunities in these applications - both to better understand the limiting mechanisms within the materials and to significantly advance the durability and predictability of device performance required for renewable energy conversion and storage.
\end{abstract}

J. G. Swallow · W. H. Woodford · Q. Lu · J. J. Kim · D. Chen ·

Y.-M. Chiang - W. C. Carter - H. L. Tuller - K. J. Van Vliet Department of Materials Science and Engineering, Massachusetts Institute of Technology, Cambridge, MA 02139, USA

Y. Chen · B. Yildiz

Department of Nuclear Science and Engineering, Massachusetts Institute of Technology, Cambridge, MA 02139, USA

K. J. Van Vliet $(\bowtie)$

Laboratory for Material Chemomechanics (8-237), Massachusetts Institute of Technology, 77 Massachusetts Avenue, Cambridge MA 02139, USA

e-mail: krystyn@mit.edu
Keywords Chemomechanics · Solid oxide fuel cells · Batteries $\cdot$ Ionically conductive ceramics

\section{Introduction}

Electrochemical energy conversion and storage devices are promising technological platforms to generate and accumulate energy stored by electrochemical processes, offering potentially high efficiency and low environmental impact. In particular, solid oxide fuel cells (SOFCs) and lithiumion batteries (LIBs) are expected to play a central role in a clean energy future that seeks alternatives to energy sources based on combustion of petroleum-based fuels and capacity to distribute energy density at low weights and volumes. SOFCs offer fuel flexibility including fossil fuels and hydrogen with reduced emissions compared to combustionbased energy generation; and LIBs offer general energy storage for a range of energy generation platforms. Despite decades of research and development in both SOFC and LIB technologies, these platforms have not substantially displaced combustion energy sources. In large-scale applications, SOFCs have been limited by high operating temperatures and durability issues [1] while LIBs are constrained by high cost and limited lifetime. After decades of intensive research and investment, why is it that these technologies continue to exhibit such challenges in device lifetime, duration, and predictability? In large part, overcoming this obstacle will require improved understanding and engineering of the materials comprising the anodes, cathodes, and electrolytes.

Both SOFCs and LIBs use nonstoichiometric, ionically conductive ceramic materials as electrodes that require facile electronic and ionic transport for high performance. In addition to the electrochemical coupling that is central 
to the operation of these devices, the materials used in both systems show strong chemomechanical coupling - i.e., interdependence of the chemical and mechanical states leading to a rich variety of phenomena. In SOFC materials, this coupling can be exploited to engineer materials with enhanced performance; in part, this is achieved by tuning of the local strain state to modulate gas exchange reactivity in the electrode phases of fuel cells [2]. In LIB materials, this same coupling can drive electrode materials to mechanical failure, resulting in impedance growth and performance degradation of batteries.

This review focuses on four major areas of current research aimed at developing fundamental understanding of electro-chemo-mechanical phenomena in SOFC and LIB materials. Throughout, we highlight similarities and differences between SOFC and LIB materials and systems. First, we survey the experimental and computational tools that have been applied to study electro-chemo-mechanical phenomena, with an emphasis on in situ characterization of mechanical, ionic, electrocatalytic, and electronic properties. Second, we explore the origin of chemical expansion in nonstoichiometric oxide materials and discuss the consequences of this phenomenon on the performance and reliability of SOFC and LIB materials. Next, we examine the effect of engineered strain states on interfacial reactions, with an emphasis on the oxygen reduction reactivity of oxides for fuel cell cathodes. Finally, we discuss the role of electrochemomechanics in enhancing the transport properties of materials, as required for efficient energy conversion and storage devices. We conclude with a discussion of how this fundamental research may be applied to improve material selection and device design, maintaining or enhancing conductivity and surface reactivity while maintaining the durability required of reliable device lifetimes.

\section{Solid oxide fuel cells and Lithium-ion batteries: operating principles}

Solid oxide fuel cells and lithium-ion batteries are both electrochemical devices that convert chemical into electrical energy, and vice versa. Notably, the materials within these devices are operated far-from-equilibrium, particularly for rapid conversion or storage/discharge of energy. These devices do not typically use the same active material compositions, but share several key material functionalities and properties, as illustrated in Fig. 1. SOFCs oxidize a fuel electrochemically, rather than by combustion, by separating ionic and electronic transport. As shown in Fig. 1(a-b), in a SOFC, the gaseous oxygen is reduced at the cathode, and then transported through the electronically insulating, ionically conductive electrolyte. The oxygen diffuses via an oxygen vacancy mechanism to the anode, where it reacts with hydrogen derived from a hydrocarbon fuel or hydrogen to produce water and release an electron back into the external circuit. Under open circuit conditions, a potential difference between cathode and anode is set up given by the Nernst potential (under ideal conditions). In the non-stoichiometric materials that comprise the cathode and anode (and potentially the electrolyte), spatial variations in oxygen vacancy concentration parallel corresponding variations in oxygen partial pressure. This gradient in vacancy concentration correlates with Vegard expansion in many non-stoichiometric oxides, an effect which is magnified at the high operating temperatures of SOFCs [3, 4].

The oxygen reduction reaction occurring at the cathode is given in Kröger-Vink notation by Eq. 1:

$\frac{1}{2} \mathrm{O}_{2(g)}+V_{\mathrm{O}}^{\bullet \bullet}+2 \mathrm{e}^{\prime} \rightleftharpoons \mathrm{O}_{\mathrm{O}}^{\times}$

where $V_{\mathrm{O}}^{\bullet \bullet}$ is an oxygen vacancy with two net positive charges and $e^{\prime}$ is an electron. For SOFCs, electrode and electrolyte materials are commonly perovskite- or fluorite-structured oxides that can tolerate large oxygen vacancy concentrations and many different atomic impurities (dopants) at high concentration. For the cathode, mixed ionic-electronic conductors such as $\mathrm{La}_{1-x} \mathrm{Sr}_{x} \mathrm{CoO}_{3-\delta}$ (LSC), $\mathrm{SrTi}_{1-x} \mathrm{Fe}_{x} \mathrm{O}_{3-\delta}$ (STF), or $\operatorname{Pr}_{x} \mathrm{Ce}_{1-x} \mathrm{O}_{2-\delta}$ (PCO) are selected, as such compounds may enhance oxygen reduction reactivity by extending active sites from simply triple phase boundaries (as for solely electronic conductors) to the full area of the electrode [4-6]. The electrolyte, on the other hand, must be both electronically insulating and highly conductive to oxide ions, and so materials such as yttria stabilized zirconia (YSZ) or $\mathrm{Gd}_{x} \mathrm{Ce}_{1-x} \mathrm{O}_{2-\delta}$ (GDC) are typically used as solid electrolytes. Lower valent dopants $A$ (Y in YSZ and Gd in GDC) are added to the electrolyte material to fix vacancy concentrations at very high levels, as described in Eq. 2 [7]:

$\mathrm{A}_{2} \mathrm{O}_{3} \rightarrow 2 \mathrm{~A}_{\mathrm{M}}^{\prime}+\mathrm{V}_{\mathrm{O}}^{\bullet \bullet}+3 \mathrm{O}_{\mathrm{O}}^{\times}$

High device efficiency requires that ionic conductivity and oxygen exchange kinetics are maximized, and also that anode materials actively catalyze fuel oxidation. Therefore, SOFCs are often operated between 600 and $1000{ }^{\circ} \mathrm{C}$, and this operating environment confers the additional materials requirement of high thermal stability.

Lithium-ion batteries operate by shuttling lithium ions between two intercalation compounds with dissimilar lithium chemical potentials. A prototypical cell uses a transition metal oxide such as $\mathrm{LiCoO}_{2}$ as a positive electrode material and a graphite negative electrode. As the battery is charged, lithium ions and electrons are removed from 
Fig. 1 Operating principles of electrochemical energy conversion and storage devices. (a) Solid oxide fuel cell (SOFC); (b) Inset of the SOFC cathode, showing the oxygen reduction reaction and oxide ion transport via the vacancy mechanism across the cathode. The cathode shape is indicative of the chemical expansion one might expect to see across the cathode. (c) Diagram of a battery. (d) Inset of the lithium-ion battery (LIB) cathode, showing the lithium intercalation reaction at the cathode, with electrons reducing cobalt while lithium ions react with lithium vacancies. The dashed line around the particle indicates the volume change associated with increased lithium content relative to the delithiated state

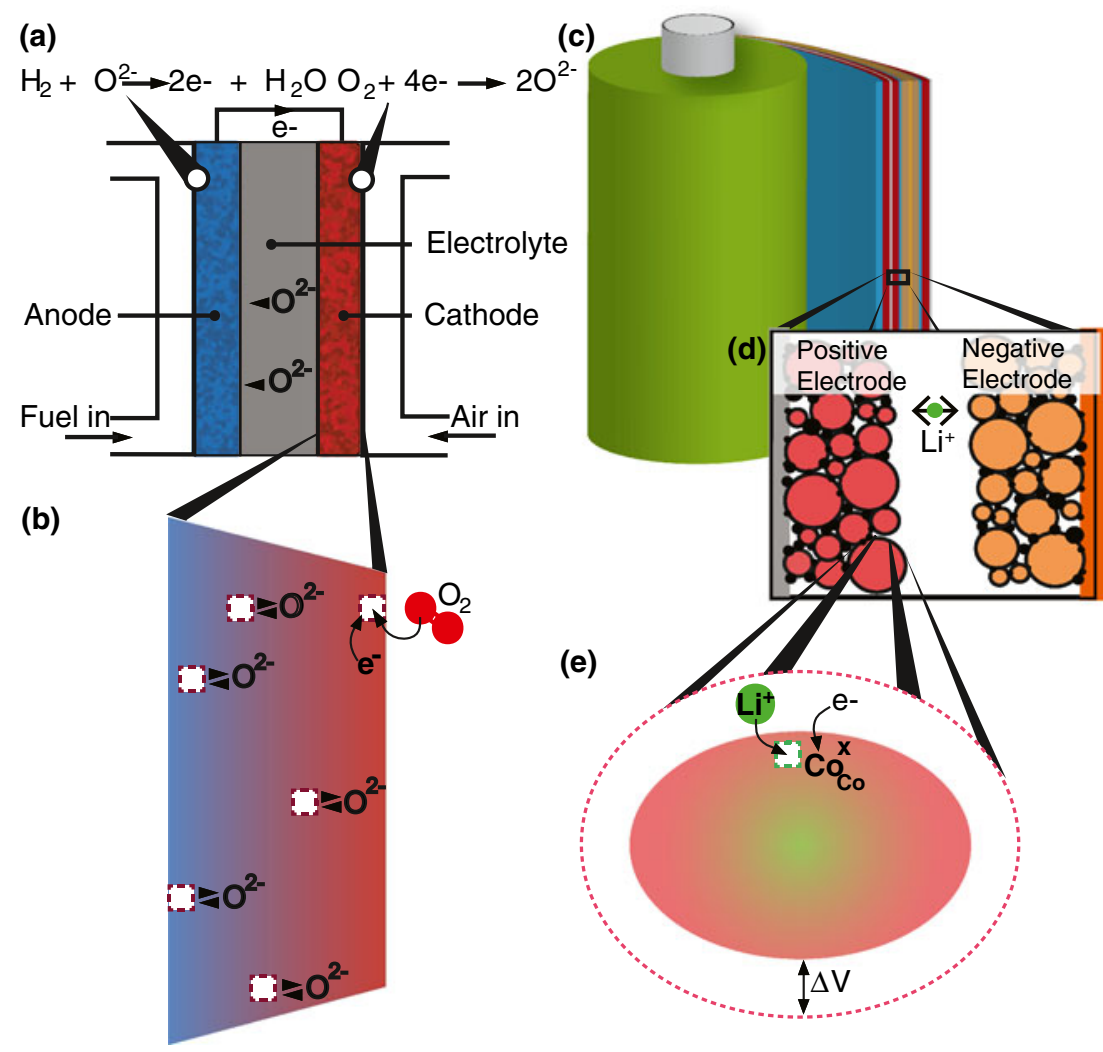

the positive electrode material and separated; the conventional half-reaction for this process is given in Eq. 3. As shown in Fig. 1(c-d), the overall reaction proceeds electrochemically because the lithium ions and electrons are separated; lithium ions travel through the electrolyte, which is an ionic conductor and electronic insulator, while electrons travel through the external circuit. At the negative electrode, lithium ions and electrons meet and are intercalated into the graphitic material, as described by Eq. 4. During discharge, the process is reversed.

$\mathrm{LiCoO}_{2} \leftrightharpoons \mathrm{Li}_{1-x} \mathrm{CoO}_{2}+x \mathrm{Li}^{+}+x \mathrm{e}^{-}$

$\mathrm{C}_{6}+x \mathrm{Li}^{+}+x \mathrm{e}^{-} \leftrightharpoons \mathrm{Li}_{x} \mathrm{C}_{6}$

To highlight the similarities in the operational principles of batteries and fuel cells, it is instructive to express the electrochemical half reactions of the LIB also as KrögerVink defect reactions. Taking as an example the delithiation of $\mathrm{LiCoO}_{2}$, and using the fully lithiated material as a reference state, the defect reaction in Kröger-Vink notation is:

$\mathrm{Li}_{\mathrm{Li}}^{\times}+\mathrm{Co}_{\mathrm{Co}}^{\times} \leftrightharpoons V_{\mathrm{Li}}^{\prime}+\mathrm{Co}_{\mathrm{Co}}^{\bullet}+\mathrm{Li}^{+}+\mathrm{e}^{-}$
This defect reaction is visualized in Fig. 1(e), which shows lithium intercalating into a cathode particle at a lithium vacancy site while an electron reduces a nearby cobalt ion.

There are three classes of lithium storage compounds used in cathodes of commercial lithium-ion batteries. These include layered lithium-containing materials, such as $\mathrm{LiCoO}_{2}$ that adopt the $\alpha-\mathrm{NaFeO}_{2}$ ordered rocksalt structure; spinel oxides such as $\mathrm{LiMnO}_{4}$; and olivines such as $\mathrm{LiFePO}_{4}$. To minimize the impedance and maximize the useful lifetime of the LIB, these materials must be fracture resistant. Repeated cycling can lead to crack propagation within cathode particles; this crack propagation can result in increased impedance and eventual device failure. As nonstoichiometry increases, the cathode materials may undergo phase transformations that can lead to failure as well.

The active materials in LIBs must reversibly take up and release large concentrations of lithium; at the materials level, the charge storage capacity is largely determined by how wide a composition change a material can tolerate without irreversible structural changes. Large shape changes typically accompany these composition changes. Figure 2 displays the development of stresses at various points in a particle in a lithium ion battery cathode during a typical charge-discharge cycle. This stress development results from changes in material volume and lithium concentration that are inhomogeneous across individual particles, and 


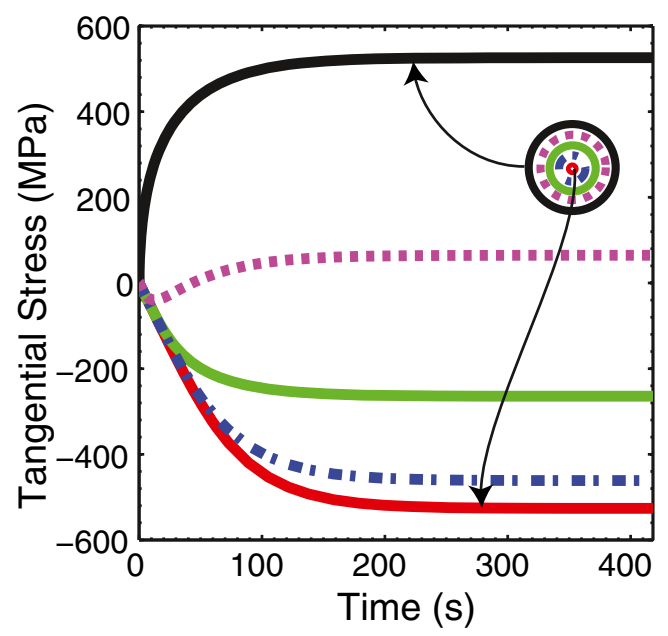

Fig. 2 Stress vs. cycle time in a cathode particle for 1 typical cycle of a lithium-ion battery. Strain (and stress) gradients arise within lithiumion battery cathode materials during charge-discharge cycles. The spherical particle represents a single cathode particle, which in practice may be a single grain or polycrystalline. Reproduced with permission from reference [10]

that vary depending on the overall state of charge and the electrochemical cycling, or C-Rate. (C-Rate is a normalized measure of the rate of charge or discharge of an energy storage device, which normalizes an applied current by the theoretical capacity; a rate of $\mathrm{C} / \mathrm{n}$ means it requires $\mathrm{n}$ hours to fully charge the device.)

While batteries must withstand frequent and repeated cycling, most solid oxide fuel cells are designed to operate continuously. However, if SOFCs are to be adapted for use in portable applications such as automobiles, these devices and materials will need to be able to withstand repeated start-up and shut-down. As even the best performing low-temperature SOFCs operate at temperatures at or above $600{ }^{\circ} \mathrm{C}$, start-up corresponds to very large temperature changes over times of only a few minutes $[8,9]$. Such rapid temperature changes, combined with the effects of chemical expansion across the device, could lead to unanticipated stress profiles developing in fuel cell electrodes and electrolytes. The chemomechanical coupling inherent in nonstoichiometric oxides may cause similar performanceimpairing effects in SOFCs as are observed currently in LIBs. However, it is also possible that mechanical strain profiles can be exploited to improve transport properties in these materials.

There exist numerous similarities between SOFCs and LIBs, as illustrated in Fig. 3. Both systems require surface exchange reactions and ionic transport through the bulk, and both systems exhibit strong electro-chemo-mechanical coupling. Vacancy concentration and nonstoichiometry affect both the ionic conductivity and the crystalline lattice parameter, producing concurrent changes in mechanical

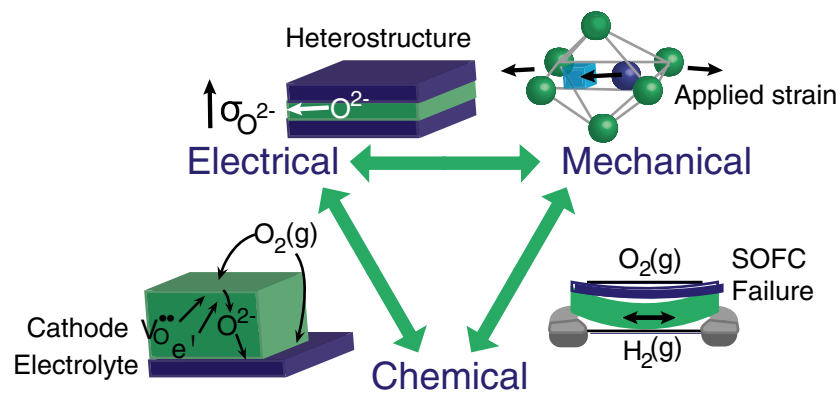

Fig. 3 Coupling among chemistry, mechanical strain, and electronic properties in non-stoichiometric ionically conductive ceramics for fuel cells and batteries. Adapted from [11]

and electronic properties. Chemical expansion leads to diffusion-induced stresses that may induce or accelerate fracture. However, it is plausible that future designs of materials and devices may exploit strain to enhance ionic conductivity. With the ultimate goal of optimizing device performance by taking advantage of this coupling, several research goals must be realized. Historically, attempts to improve the mechanical stability of these materials have also changed the transport properties, and therefore the energy conversion efficiencies. Likewise, approaches seeking to improve transport and device efficiencies through new material compositions or microstructures have been limited inadvertently by reduced lifetime and fracture resistance. Future research and development to enhance these devices beyond these current limitations must exploit this coupling, optimizing for both device efficiency and mechanical stability.

Finally, we note that these key electrochemical processes require functionality over many length scales, from the atomic scale of the oxygen reduction reaction on the SOFC cathode surface, to the diffusion length of $\mathrm{Li}^{+}$or $\mathrm{O}^{2-}$ ions, to the scale of entire devices. As a result, reduced system sizes can have profound effects on the performance and electro-chemo-mechanical phenomena in both systems. In fuel cells, thin film electrodes and electrolytes decrease the overall resistance of the cell; this scale reduction can also reduce operating temperatures $[8,12]$. Another consequence of using thin films in fuel cells is the production of steeper oxygen partial pressure gradients, and therefore lattice parameter gradients, across membranes, potentially giving rise to strains that could change the other properties of the materials. Furthermore, the use of thin films extends possibilities for exploiting interfacial effects to improve the functionality of fuel cells. Thin films may be fabricated with high compositional precision and may be designed with engineered strain states. Thus, mechanical variables offer another mechanism for tuning the performance of materials, such as by enhancing ionic conductivity or interfacial reactivity. In contrast to the advantageous effects of strain 
in SOFC cathodes, the electro-chemo-mechanical couplings in LIB cathodes are manifested primarily as large shape changes that induce severe and heterogeneous stress states, ultimately leading to fracture of active particles. As a result, the active particle microstructures must be chosen to minimize or avert particle fracture under specified duty cycles of the battery $[13,14]$. To consider and quantify this coupling in SOFCs and LIBs, we will next outline the experimental and computational methods that have been developed for both fundamental study and practical design of the ionically conductive compounds. We emphasize the advent of in situ methods, as these allow the most direct correlation between the functional operating environment and chemomechanical properties of interest.

\section{Methods}

The study of the electro-chemo-mechanics in ionically and mixed ionically-electronically conductive ceramics must necessarily incorporate both computational and experimental methods, with an emphasis on in situ characterization tools that can be used to observe the far-from-equilibrium processes that are fundamental to the operation of these devices. Interest in strain effects at interfaces and surface reactivity point to thin film fabrication methods as a cornerstone of experimental research into electro-chemomechanics, and for this reason we first discuss several thin film fabrication methods here, including the pulsed laser deposition approaches that have enabled synthesis of thin films with complex stoichiometry.

\subsection{Material processing}

After the successful growth of high temperature superconducting films in 1987, pulsed laser deposition (PLD) has been widely used to fabricate high quality thin films of many different materials with complex chemistries [15]. As the name implies, PLD utilizes a high power pulsed laser beam to supply energy to target materials so that they are vaporized and transported to a substrate surface [16]. The incident laser pulse penetrates only the outermost surface of the target material (typically about $10 \mathrm{~nm}$ depth), causing a rapid increase in surface temperature (up to about $10^{3}{ }^{\circ} \mathrm{C}$ ) [17]. One advantage of the PLD technique derives from this high heating (or evaporation) rate, which effectively enables all target constituents to be evaporated at the same time. As a result, PLD allows transfer of multi-component target materials onto a substrate with little change in chemical composition. In contrast, it is generally difficult to control the stoichiometry of the resulting thin film with other physical vapor deposition (PVD) techniques such as sputtering or electron beam evaporation. Another advantage of
PLD is that it utilizes a highly confined plume of materials, which produces films with less contamination and high reproducibility. On the other hand, contamination of the source materials by the container is hardly avoidable in thermal and electron beam evaporation. In methods that use organic materials such as ink-jet printing, and metal organic chemical vapor deposition (MOCVD), the potential of leaving organic residues behind in the films exists. Additionally, PLD provides many accessible operating parameters that can be separately controlled, including laser power, pulse rate, background pressure, gas composition, substrate surface temperature, and crystallographic orientation of the substrate. Therefore, PLD provides a facile method for modifying the attributes of thin film microstructure, such as crystal orientation, grain size, and shape. Lastly, PLD opens up a more convenient route for fabricating multilayer systems or single films with compositional variations. This can be easily realized by rapidly rastering the laser beam between different targets under computer controlled conditions [18, 19].

\subsection{Material characterization}

In situ characterization methods are essential for developing a full understanding of the electro-chemo-mechanics of ionically conductive ceramics. Here, we discuss many of the in situ characterization methods currently in use or under development that could be used to study electro-chemomechanical coupling in these materials.

\subsubsection{Chemical, structural, and morphological}

Examining the electronic structure confined to the nanometer scale near an interface is a well-known challenge in the study of heterointerfaces [20, 21]. Synchrotron X-rays [21] and combinations of scanning transmission electron microscopy and electron energy loss spectroscopy (EELS) $[20,22]$ have been successfully used for obtaining localized electronic information on oxide hetero-interfaces. Scanning probe techniques are ideal for studying local electronic, magnetic, or electrochemical properties on surfaces [2326]. Even more challenging is to access interfaces buried within multilayered structures. A novel approach for exposing the interface in multilayer structures was recently developed, using shallow angle focused ion beam (FIB) milling which expands the interface region from the nanometer to the micrometer scale, facilitating the characterization of interfaces by scanning tunneling microscopy/spectroscopy (STM/S). Figure 4 schematically shows how a combination of FIB milling and STM can be used to study the electronic structure near interfaces, first demonstrated at room temperature with a superlattice of ( $\mathrm{La}, \mathrm{Sr}) \mathrm{MnO}_{3}(\mathrm{LSM})$ and STF [19]. This method has been further extended recently to high 
Fig. 4 Focused ion beam enables exposure of buried interfaces, which can then be interrogated via scanning probe microscopy. Reproduced from Ref [19] with permission from John Wiley and Sons (a)



(c)

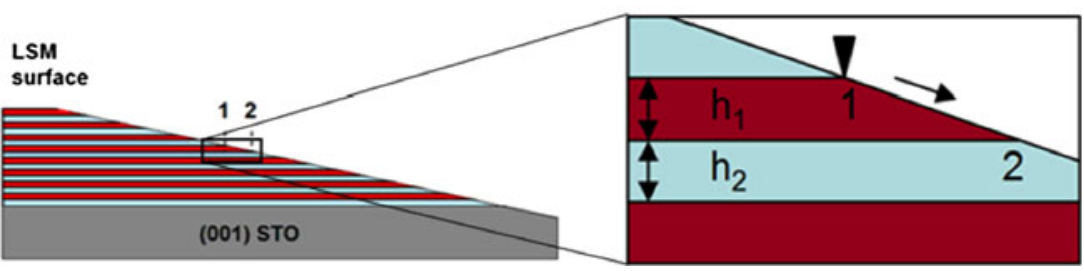

temperatures and an oxygen gas environment by combining FIB and in situ STM/S [27], thereby demonstrating for the first time the ability to probe the electronic structure across heterointerfaces with nanoscale resolution at high temperature and in an oxygen/gas environment. Such information is essential to understanding the kinetics of oxygen reduction near heterointerfaces, and can be applied to materials beyond oxides for SOFCs.

High temperature X-ray diffraction can be used to study the long-range order, lattice parameter, crystallite size, and microstrain in materials and therefore track temperaturedependent expansion and resulting strains within materials with different compositions, as was reported by Kuru et al. for PCO [28]. Using thin film electrodes, quantitative measurements of film stresses have also been made via laser deflection methods for $\mathrm{LiMn}_{2} \mathrm{O}_{4}$ [29], $\mathrm{LiCoO}_{2}$ [30], and for composite graphite negative electrodes in LIBs [31] .

Direct measurement of stresses within films can also be used to study information about oxygen exchange. Yang et al. and Sheldon et al. made in situ measurements of the curvature of thin films of $\mathrm{La}_{0.6} \mathrm{Sr}_{0.4} \mathrm{FeO}_{3-\delta}$ and ceria, respectively, using multi-beam optical stress sensors (MOSS) [32, 33]. Yang et al. used these measurements to determine film stress and chemical oxygen surface exchange coefficients as functions of temperature and oxygen partial pressure, while Sheldon et al. related compositional stresses to grain boundary width and established the influence of space charge effects on oxygen incorporation thermodynamics.

Optical absorption spectroscopy provides a simple nondestructive means of detecting nonstoichiometry changes in complex compounds. Optical absorption experiments detect characteristic optical peaks related to specific defect species or valence states of ions, and are particularly advantageous in characterization of oxides. For example, $\mathrm{Cr}^{3+}$ ions in alumina give a red color to the crystal because the octahedral ligand field induced by surrounding oxygen ions causes a d-orbital energy level splitting of $\mathrm{Cr}$ ions [34]. Valence states of certain cations change under oxidizing and reducing conditions, which can induce optical absorption changes in specific spectral regions as a function of oxygen partial pressure and temperature. Because concentrations of cations and compensating defect species (e.g., oxygen vacancies) are coupled via the defect charge neutrality relation, optical absorption measurement allows investigation of the equilibrium properties of defects as well as reaction kinetics. After some studies on oxide single crystals were reported $[35,36]$, more recently some of the present authors have demonstrated that in situ optical absorption measurements can be a powerful means for monitoring oxygen nonstoichiometry and surface exchange kinetics in oxide thin films $[37,38]$. For example, optical absorption of PCO in the visible spectrum was tied to the fraction of $\mathrm{Pr}$ in its oxidized state $(4+)$, which in turn could be related to the oxygen deficiency of the material. In contrast to electrochemical measurements, these optical studies require no metal contacts, which can introduce possible catalytic activity and/or space charge effects. Furthermore, optical absorption measurements enable the study of oxygen nonstoichiometry changes in thin films; they overcome the limitations of the thermogravimetric analysis (TGA) technique which is inappropriate for thin films due to the very small magnitude of mass change. 
Detailed, microstructurally resolved models of device performance and failure (e.g., of battery cathode materials) require accurate microstructural information. To this end, fully three-dimensional microstructure characterization is necessary. A variety of tomographic methods have been applied to battery electrodes to better understand these complex heterogeneous microstructures by facilitating evaluation of porosity, tortuosity, and surface area, and to inform more realistic models of electrode function and failure. X-ray tomography has been used to non-destructively reconstruct composite electrodes $[39,40]$ as well as monolithic porous $\mathrm{LiCoO}_{2}$ samples [41]. A second, destructive, option for reconstructing 3-D electrode microstructures is serial imaging with a dual-beam focused ion beam-scanning electron microscope (FIB-SEM). This technique was used by Wilson et al. and Clague et al. to reconstruct Ni-YSZ anode microstructures $[42,43]$. Clague et al. converted this 3-D structure into a mesh for finite element (FE) simulation of stresses developing within the material as temperature increased. The FIB-SEM method was also used to visualize the active material in a $\mathrm{LiCoO}_{2}$ composite electrode [44], and could potentially be used to develop simulations of chemical expansion in realistic electrode structures. Section 4 discusses the phenomenon of chemical expansion in further detail.

X-ray photoelectron spectroscopy (XPS) is a useful technique for determining surface chemistry and electronic structure with near-surface depth resolution. It can be used to detect local changes in chemical states and draw conclusions about the size of electrochemically active regions or correlations between surface chemistry and environmental conditions. In situ XPS measurements are especially important for mechanistic insight into electro-chemo-mechanical coupling in materials for SOFCs and batteries, as many of these phenomena are accompanied by changes in surface chemistry and electronic structure at elevated temperature. Cai et al. used angle resolved X-ray photoelectron spectroscopy (ARXPS) to study the reversible reduction of cobalt in strained $\mathrm{La}_{0.8} \mathrm{Sr}_{0.2} \mathrm{CoO}_{3}$, a phenomenon associated with increased surface vacancy concentrations, at high temperature in vacuum [45]. Zhang et al. further performed ambient in situ synchrotron XPS to characterize $\mathrm{CeO}_{2-\delta} / \mathrm{YSZ} / \mathrm{Pt}$ cells and establish the relation between the kinetic energy shift of the core-level spectra and the local surface potential and local overpotentials of the cell components [46]. Mutoro et al. combined oxygen-atmosphere with external electrochemical potential and found reversible compositional changes in LSC thin films at elevated temperature [47]. In situ XPS will facilitate insightful advances in understanding chemomechanical processes in SOFCs and batteries, including the mechanisms of surface reactivity and transport that are essential to the functionality of these devices.
Scanning probe microscopy (SPM) generally encompasses many different surface characterization techniques capable of mapping surface topography, strain, conductivity, electronic structure, and surface potential, and measuring changes in these variables resulting from applied bias, current, or changes in environmental conditions [48]. In situ wet cell scanning probe microscopy of $\mathrm{V}_{2} \mathrm{O}_{5}$ and $\mathrm{MoO}_{3}$ thin films revealed surface roughening and potential buckling instabilities with lithium cycling $[49,50]$. Chen et al. used a combination of in situ scanning tunneling spectroscopy and focused ion beam milling (Fig. 4) to uncover the local electronic structure of $\left(\mathrm{La}_{0.5} \mathrm{Sr}_{0.5}\right)_{2} \mathrm{CoO}_{4+\delta}$ and $\left(\mathrm{La}_{0.8} \mathrm{Sr}_{0.2}\right) \mathrm{CoO}_{3-\delta}$ interfaces in a superlattice structure, in relation to the oxygen reduction reactivity of this heterostructured system [27]. Kalinin et al. have reported numerous studies utilizing in situ scanning probe microscopy for observing electro-chemo-mechanical phenomena in materials for both SOFCs and LIBs. Leonard et al. used electrochemical strain microscopy (ESM), a type of SPM that applies a bias voltage to a surface and measures the surface displacement that results, to investigate the kinetics of the oxygen reduction reaction on a $\left(\mathrm{La}_{0.5} \mathrm{Sr}_{0.5}\right)_{2} \mathrm{CoO}_{4+\delta}$ modified $\left(\mathrm{La}_{x} \mathrm{Sr}_{1-x}\right) \mathrm{CoO}_{3-\delta}$ surface [51]. Balke et al. also used ESM to map the diffusivity of lithium in individual grains and grain boundaries of $\mathrm{LiCoO}_{2}$, locating and visualizing grain boundaries and grain orientations with enhanced diffusivity [52]. It is worth noting that this technique, which is visualized in Fig. 5, is enabled directly by the electrochemo-mechanical coupling of the materials being studied: applying a bias to the material induces charge transport that in turn causes changes in surface morphology that can be detected by the probe. Thus, ESM is particularly well-suited to studying electro-chemo-mechanical phenomena. Indeed, SPM generally encompasses a rich variety of techniques that can be used to study different attributes of functional ionically conductive ceramics.

\subsubsection{Transport and reactivity}

Scanning tunneling microscopy and spectroscopy (STM, STS) are widely used to characterize the morphology and electronic structure of surfaces. Compared to XPS which can also provide electronic structure information, STM/S is more surface sensitive and has much greater lateral resolution, as fine as the atomic scale. Traditionally, these techniques have been used at room temperature or low temperature under ultra-high vacuum. Investigation of the electronic structure of the surface under operando conditions benefits from customized STM/STS capabilities. This enables measurements at elevated temperature in an oxygen gas environment, allowing closer simulation of the real environment of SOFCs. Reversible changes in electronic structure with temperature have been observed on the 


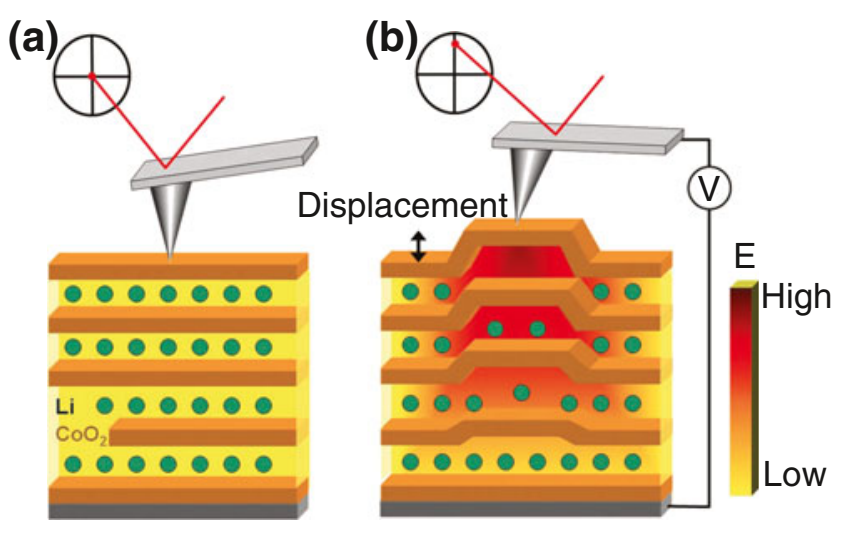

Fig. 5 Scanning probe microscopy enables direct measurements of surface morphology changes related to charge transport and surface reactivity. An SPM tip initially in contact with a surface (a) is deflected by local volume expansion resulting from charge redistribution due to an applied electrical field (b). Reproduced from Ref [48] with permission from John Wiley and Sons

surfaces of several widely studied SOFC cathode materials, including LSC, LSM, and STF [27, 45, 53-55]. The reversible nature of these changes means that ex situ techniques do not capture the phenomena of interest. Using this in situ capability, Cai et al. and Jalili et al. found that tensile strain of films comprising either LSC or LSM have larger densities of states as compared to films under compressive strain at higher temperature $[45,53]$. These results provide insight into the strain and reactivity correlation of SOFC cathode materials.

Isotope exchange depth profiling (IEDP) in combination with time of flight secondary ion mass spectroscopy (ToFSIMS) has been used to determine the diffusion coefficients and oxygen surface exchange rates for several materials relevant to SOFCs [2, 56, 57]. Zapata et al. used this method to determine the anisotropic diffusion coefficients and surface exchange rates of oxygen in thin films of the double perovskite $\mathrm{GdBaCo}_{2} \mathrm{O}_{5+\delta}$. They found that the diffusion coefficient was highly anisotropic, while the surface exchange rate was independent of film orientation.

Impedance spectroscopy (IS) is a powerful technique for studying electrochemical systems. Specifically, IS can be used to deconvolute resistive and capacitive contributions from the electrolyte and electrodes, bulk and interfacial effects, and equilibrium and kinetic processes, including the ability to study electrode kinetics (exchange or diffusion limited, rate coefficients, etc.) $[58,59]$. In these systems, reaction or migration steps are coupled, and each step has an associated characteristic frequency. Typically IS is performed over a wide frequency range, making it possible to deconvolute these steps in the frequency domain. As a consequence, IS is routinely used as a characterization technique for electrochemical energy storage and conversion devices such as SOFCs [60] and LIBs [61-63]. IS is particularly well-suited to the study of fundamental electrochemistry when combined with thin film sample geometries. The reactions or migration steps in electrochemical systems have characteristic geometric dependences. Thus, the well-defined and reproducible geometry of thin films enable one to more readily identify the reaction sites and isolate the functional steps controlling kinetic processes. The key material properties and processes that can impact the performance of SOFCs and LIBs, such as oxygen reduction reaction rates, mass and transport properties, and nonstoichiometry, can all be studied using this approach. For example, Baumann et al. and Jung et al. isolated the limiting oxidation reactions on perovskite-type SOFC cathode materials and thus extracted the oxygen surface resistance, which is inversely proportional to chemical oxygen exchange rate [6, 64]. Fleig et al. derived an equivalent electrical circuit to describe the performance of a $\left(\mathrm{La}_{0.8} \mathrm{Sr}_{0.2}\right)_{0.92} \mathrm{MnO}_{3}$ cathode, which allowed the separation of contributions to the electrode impedance from surface oxygen exchange and oxide ion diffusion through the film electrode [65]. Most recently, Chueh et al. and Chen et al. studied the nonstoichiometry of anode and cathode materials, respectively, by analysis of chemical capacitance values extracted from IS measurements on thin films $[59,66]$.

\subsubsection{Mechanical, elastoplastic, and fracture properties}

The experimental methods listed so far have focused on measuring chemical, morphological, or structural changes in situ. However, methods for measuring mechanical properties in situ are also essential to advancing the understanding of electro-chemo-mechanical phenomena in these materials, particularly if devices are to be developed that achieve both mechanical durability and energy conversion efficiency. To that end, we highlight several in situ methods for mechanical characterization. This analysis includes both the mechanical properties of the active compounds (e.g., stiffness and hardness) as well as fracture onset and progression.

Transmission electron microscopy (TEM), with attendant atomic level resolution and ability to image defects in specimens with high detail, has been used previously to study fracture and stress development in battery electrode materials post mortem [67]. Using in situ wet cell scanning electron microscopy of an individual polycrystalline electrode particle with a focused ion beam (FIB)-created window, Miller et al. observed the development of many internal intergranular cracks during the first electrochemical cycle [68]. Digital image correlation methods have been applied to conventional composite electrodes to track macroscopic deformations $[69,70]$. With recent advances in TEM technology, in situ studies of miniature operating LIBs 
have become possible. Wang et al. developed a specialized in situ TEM cell connected to a battery testing system to observe by TEM and EELS the microstructural evolution of a miniature battery constructed of a $\mathrm{SnO}_{2}$ nanowire anode, an ionic liquid electrolyte (ILE), and a $\mathrm{LiCoO}_{2}$ cathode [71]. Huang et al. imaged the real-time charging and discharging of a similar $\mathrm{SnO}_{2} / \mathrm{ILE} / \mathrm{LiCoO}_{2}$ battery [72] and observed volume and shape changes associated with the charge and discharge cycle, as well as the displacement of the reaction interface and the generation and migration of dislocations nucleated at the highly stressed reacting interface. The availability of high temperature TEM [73] combined with the potential to visually observe events in real time suggests that this technique might also be applied to study electro-chemo-mechanical phenomena in nonstoichiometric oxides for SOFCs. While the oxidizing and reducing atmospheres required for true in situ studies of cathode or anode materials complicate this possibility, observing effects related to applied electrical biases may still be possible. Finally, beyond direct observation of cracks in materials or devices, acoustic emission has emerged as a tool for non-destructive, in situ monitoring of particle-level fracture in battery materials. Acoustic emission has been used to study conversion-type materials [74], silicon anodes [75], electrolytic $\mathrm{MnO}_{2}$, [76-78], and $\mathrm{LiCoO}_{2}$ [14]; similar measurements were also used to study fracture of metal-hydride battery electrodes [79].

Kawada et al. employed the resonance method to measure the elastic moduli of brittle compounds at high temperatures and under controlled atmospheres. This method applies flexural and torsional oscillations to samples of known geometry, enabling specific elastic moduli to be determined from the measured resonant frequencies [8082]. This approach also provides measurement of the internal friction of these materials. Researchers from that Tohoku University-based team have also developed a device that can estimate the fracture stress and elastic modulus in similar high temperature, controlled atmosphere environments using a small punch [83, 84]. Alternatively, instrumented nanoindentation is under development for environmentally controlled, in situ analysis of elastoplastic and fracture properties. Recent demonstrations of nanoindentation hardness and elastic modulus measurement capabilities as high as $750{ }^{\circ} \mathrm{C}$ suggest that this could be a method for characterizing the mechanical properties of oxides for SOFCs [85]. As compared to the small punch and resonance method techniques, nanoindentation is capable of measuring mechanical properties of thin films, and can also be used to measure the fracture toughness of single grains, as has been reported recently for $\mathrm{LiCoO}_{2}$ [86].

\subsection{Computational modeling and simulation}

These experimental methods, while essential to understanding the phenomena that occur in ionically and mixed conductive ceramics, are time consuming and the information gained is often material specific. Computational methods enable complementary analysis of the wide and interdependent phase space of electro-chemo-mechanically coupled, conductive ceramics, and so we discuss a few of these methods here.

\subsubsection{Atomistic modeling}

Atomistic modeling is a useful method for determining the elastic properties of compounds such as $\mathrm{Li}_{X} \mathrm{FePO}_{4}$ [87] and lithiated graphite [88]. Density functional theory (DFT) is a type of atomistic modeling that can be used to investigate the electronic structure of materials and a wide range of related properties, such as the elastic constants [89], the energy barrier to vacancy migration [90] and the diffusion coefficients of various point defects [91] or, in combination with molecular dynamics (MD) simulations, the chemical expansion behavior of a given material [92].

Marrocchelli et al. used DFT $+\mathrm{U}$ (indicating inclusion of a Hubbard term) to calculate the effect of charge delocalization on the chemical expansion coefficient of $\mathrm{CeO}_{2-\delta}$ and $\mathrm{BaCeO}_{3-\delta}$ [92]. In that study, varying the $\mathrm{U}$ term changed the extent of localization of $4 \mathrm{f}$ electrons at the ceria cation. Increased localization led to increased chemical expansion coefficients for these oxides. This study exemplifies one major advantage of computational techniques in that they can artificially isolate the contributions of individual variables in a given material system that would be unavoidably coupled to changes in other variables in experimental systems. DFT + U also may be used in a predictive capacity; Dholabhai et al. also used DFT $+\mathrm{U}$ to predict the activation energies of vacancy formation and migration in PCO, and used these results with kinetic lattice Monte Carlo (kMC) simulations to calculate the doping level that would maximize ionic conductivity [93, 94]. A similar approach combining DFT and kMC was implemented by Kushima and Yildiz to predict the strain response of oxygen ion diffusion kinetics in YSZ [90].

\subsubsection{Continuum modeling}

Continuum-level models for lithium batteries have traditionally fallen into two broad classes of single-particle models and macrohomogeneous porous electrode models, in which the microstructure's heterogeneity is volume-averaged out. More recently, two- and three-dimensional models have been developed which embrace the microstructural heterogeneity in real battery electrodes. Most continuum-level 
models of chemomechanical coupling have been developed to estimate diffusion-induced stresses-analogous to thermal stresses-which develop in the presence of a concentration gradient. A variety of single-particle models have been developed to estimate diffusion-induced stresses for battery electrode materials subjected to common electrochemical protocols [95-97] and incorporating a variety of effects including limited solid-solubility [98-100], particle shape [101, 102], composition-dependent elastic modulus [103], and internal porosity [104]. Other particlelevel models have been developed which apply fracture mechanics failure criteria to study mechanical degradation of electrode materials, but these models considered static configurations - essentially the limit of zero rate-to identify critical length scales using fracture mechanics failure criteria. Aifantis et al. studied cracking in composite anodes composed of active particles embedded in inert, brittle, matrices $[105,106]$ and $\mathrm{Hu}$ et al. modeled cracks in twophase $\mathrm{LiFePO}_{4} / \mathrm{FePO}_{4}$ particles with interface coherency stresses with fully anisotropic elastic constants and stressfree strains [107].

Mean field porous electrode models developed by Newman et al. [108-113] have been extended to incorporate elastic stress predictions in individual electrode particles [114-118]. Some models have been extremely sophisticated, with detailed descriptions of electrochemical kinetics and chemomechanical couplings [99, 119].

Microstructurally resolved models have been developed which embrace the heterogeneity in commercial battery electrodes in the estimation of electrochemical reactivity and mechanical stress evolution. García et al. have developed finite element models using experimentallydetermined microstructures in two and three-dimensions and have applied these models to the calculation of particlelevel stresses in composite electrodes [120, 121]. This approach embraces the heterogeneity in composite electrodes, including differences in local reaction rates and the actual size and shape of storage particles. Figure 6 shows how finite element computations by Smith et al. predict that lithium deintercalation will proceed faster for smaller graphite particles in the anode [121]. Similar computational methodologies have been applied to study mechanical stress evolution in individual particles; for example Chung et al. included measured composition-dependent diffusivity and a measured, irregular particle shape in a single-particle 3-D finite element model [122].

\section{Chemical expansion in ionically conductive ceramics}

Both lithium intercalation compounds in LIBs and nonstoichiometric oxides in SOFCs expand or contract as ions are transported in and out of the material. These "breathing modes" could be detrimental - leading to fracture, or advantageous - leading to enhanced transport properties. The effect of chemical expansion is compounded at high temperatures by the effect of thermal expansion. Increases in lattice parameter resulting from thermochemical expansion correlate with reduced elastic moduli [81]. Additionally, higher temperatures may correspond to changes in failure mechanism: materials that fracture at low temperature may undergo plastic deformation at high temperature for the same mechanical loads. Understanding the thermochemical expansion behavior of nonstoichiometric materials is critical in identifying optimized conditions for material kinetics, charge transport, and durability.

Chemical expansion has been observed in many oxide conductors, including $\mathrm{CeO}_{2-\delta}, \mathrm{GDC}, \mathrm{La}_{0.2} \mathrm{Sr}_{0.8} \mathrm{Fe}_{0.55}$ $\mathrm{Ti}_{0.45} \mathrm{O}_{3-\delta}$, and $\mathrm{La}_{0.6} \mathrm{Sr}_{0.4} \mathrm{Co}_{0.2} \mathrm{Fe}_{0.8} \mathrm{O}_{3-\delta}$ (LSCF6428) [123-126]. Hong and Virkar used the concept of the oxygen vacancy radius to explain the measured lattice parameters and densities of doped $\mathrm{CeO}_{2}$ [127]. Bishop et al. found by dilatometry that LSCF6428 undergoes chemical expansion linearly with increased nonstoichiometry, but that this chemical expansion is independent of temperature [128]. Chemical expansion was also observed in powders of PCO by in situ X-ray diffraction [28]. The kinetics of this expansion, including the chemical surface exchange coefficient, were measured in situ for thin films of PCO by high temperature XRD and optical absorption, and for bulk samples by dilatometry, for which the diffusivity was also measured [129]. A finite difference predictive model was developed to describe the stresses that develop as a result of oxygen vacancy concentration gradients and the corresponding chemical expansion mismatch after rapid quenching of a slab of PCO [130]. Using a combination of MD and DFT, Marrochelli et al. simulated chemical expansion in PCO and YSZ, finding that it resulted from the net effect of lattice contraction from vacancy formation and lattice dilation due to simultaneous cation radius change upon reduction [3]. Marrocchelli et al. suggested that zero chemical expansion in a material could be obtained by choosing material compositions that balance these two effects. In later, related work, Marrocchelli et al. determined that charge localization at the cation increased chemical expansion relative to a structure with distributed charge [92]. With localized charge, the change in the radius of ceria upon reduction would be greater than if the charge were delocalized, causing an increase in chemical expansion for structures with higher degrees of charge localization. To a large extent, this effect also explains the difference between the chemical expansion coefficients of fluorite and perovskite oxides, as demonstrated in the same work.

Thermochemical expansion is expected to contribute to changes in mechanical and electrical properties and stability of materials [7]. However, the mechanical properties 
(a)

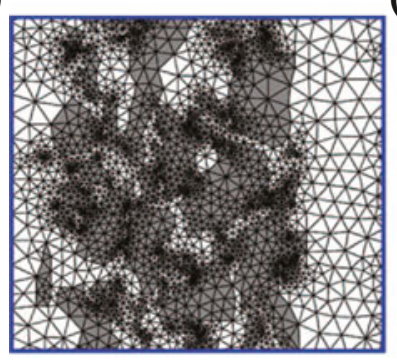

(b)

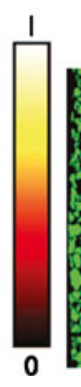

$40 \mathrm{~s}$



$840 \mathrm{~s}$

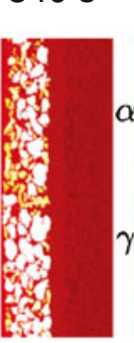

$1640 s$

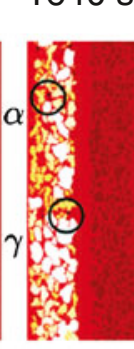



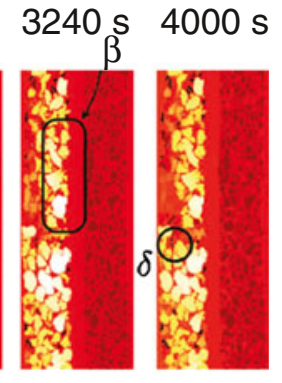

Fig. 6 2-D finite element calculations of porous electrodes from Ref [121]. Finite element mesh (a) and results showing composition fields in the solid phases and electrolyte (b) for different snapshots during galvanostatic cycling. Reproduced by permission of The Electrochemical Society

of oxides for SOFC applications have been documented chiefly for ambient conditions and room temperature. Kanchana et al. predicted several mechanical properties including the Young's elastic modulus and shear elastic modulus of $\mathrm{CeO}_{2}$ using density functional theory [89]. Morales et al. found that the elastic modulus, fracture toughness, and hardness of bulk GDC decreased with increased Gd content [131]. In contrast, Korobko et al. found that the elastic modulus of GDC was independent of doping level, but that the magnitude of creep decreased with increasing Gd content [132]. Indeed, studies on the elastic modulus of GDC have found significantly different results depending on the method of measurement [133]. Such measurements will also vary depending on the sample preparation. For example, Karageorgakis et al. observed by nanoindentation that the elastic modulus and hardness of thin films of flame-sprayed GDC peak at an annealing temperature of $900{ }^{\circ} \mathrm{C}$ [134].

It is possible to measure mechanical properties after vacancies have been "frozen in", by rapidly quenching samples from high temperature. Wang et al. found by nanoindentation of pressed, sintered, and quenched samples that the elastic modulus of GDC decreased with decreasing oxygen partial pressure $\left(\mathrm{P}_{\mathrm{O}_{2}}\right)$, but that the elastic modulus of YSZ remained unchanged [135]. Hashida et al. found similar trends for the Young's modulus of quenched samples of GDC and YSZ measured by the small punch method, finding also that the fracture stress of GDC decreased by about $80 \%$ when the oxygen partial pressure during annealing was decreased from atmospheric to $10^{-22} \mathrm{~atm}$, while the fracture stress of YSZ remained nearly the same [136]. The mechanical properties of YSZ are affected by temperature, however; Atkinson and Selçuk summarized measurements showing that the Young's modulus, mean strength, and fracture toughness of YSZ decrease when the temperature is increased from room temperature to $800{ }^{\circ} \mathrm{C}$. In contrast to Hashida et al.'s findings, those authors found that the elastic modulus of GDC remained unchanged at $800{ }^{\circ} \mathrm{C}$, and that the mean strength of GDC and LSM increased with temperature [137].
The sample quenching method poses one potential advantage: quenching enables isolation of the effect of vacancy concentration from that of temperature. At high temperatures, enhanced species mobility and thermal expansion will combine with the effects of chemical expansion to increase the complexity of material behavior. However, thermal stresses that may result from the rapid quenching process could distort mechanical testing results. Indeed, Watanabe et al. found that the fracture stresses of quenched samples of GDC annealed at low $\mathrm{P}_{O 2}$ were low relative to those measured in situ, and attributed this difference to the effect of quenching the samples [84].

There have been several studies predicting the strains that develop due to thermal and chemical expansion within nonstoichiometric oxides. Clague et al. concluded from a three-dimensional finite element model of a Ni-YSZ half cell constructed from FIB data that stresses arising at the Ni-YSZ interface due to thermal expansion were in excess of the yield stress of $\mathrm{Ni}$, and that plastic deformation was a likely mechanism to relieve stresses during temperature change [43]. Atkinson and Ramos found that the stresses induced by chemical expansion across the membranes of fuel cells in planar or cylindrical geometries were very similar, but that ceria would likely not be mechanically stable above $750{ }^{\circ} \mathrm{C}$, while perovskite-structured oxides would be stable up to higher temperatures [138]. Krishnamurthy and Sheldon developed a continuum model for the stresses arising from expansion resulting from nonstoichiometry gradients across a planar GDC electrolyte fuel cell during operation [139]. They found that when interfacial reaction kinetics were rate limiting, the stress gradient across the electrolyte was very small, while the gradient across the electrolyte was much larger when diffusion kinetics were rate limiting. Low temperatures corresponded to the reaction rate limited case, so the authors concluded that operating the cell below $700{ }^{\circ} \mathrm{C}$ was best for mechanical stability.

Sato et al. used the finite element method to model the stresses that developed in a layered fuel cell containing a 
$\mathrm{Ni}-\mathrm{Sm}_{0.2} \mathrm{Ce}_{0.8} \mathrm{O}_{2-\delta}$ cermet anode, a $\mathrm{Sm}_{0.2} \mathrm{Ce}_{0.8} \mathrm{O}_{2-\delta}$ electrolyte, and a LSCF6428 cathode [83]. They found that the stresses resulting from chemical expansion when operating above $655{ }^{\circ} \mathrm{C}$ would exceed the fracture stress of the cathode measured experimentally by the small punch method, and that operation above $680{ }^{\circ} \mathrm{C}$ would produce stresses exceeding the fracture stress measured experimentally for the electrolyte. Therefore, stresses arising from chemical expansion in operating fuel cells can be expected to cause fracture and failure of materials, especially at high temperatures. However, the precise mechanisms that contribute to this fracture and failure are incompletely understood.

The lithium-storage compounds used in lithium-ion batteries undergo large compositional changes, which enable high storage capacities. However, these composition changes are often accompanied by large shape changes, with most transition metal oxide materials exhibiting stressfree strains on the order of a few percent. The details of the shape change depend on both the crystal symmetry and phase-behavior of the lithium-storage compound, and the materials of commercial and research interest display a wide variety of composition-induced strains, which are readily characterized by X-ray diffraction.

Four different examples of composition-dependent lattice parameters observed in Li-storage compounds are shown in Fig. 7. The most straightforward system is the cubic spinel polymorph of $\mathrm{Li}_{X} \mathrm{TiS}_{2}$, shown in panel (a), which has continuous solid-solubility of lithium and a linear variation of lattice parameter with changing composition [140]. This simple behavior is, however, unusual, as the cubic spinel polymorph of $\mathrm{Li}_{X} \mathrm{TiS}_{2}$ is one of few materials displaying this behavior. The opposite extreme is exemplified by $\mathrm{Li}_{X} \mathrm{FePO}_{4}$, shown in panel (b), which has negligible solid-solubility and an anisotropic transformation strain [141]. In this material, changes in lithium composition are accomodated almost entirely by a first-order phase transformation between $\mathrm{Li}_{\alpha} \mathrm{FePO}_{4}$ and $\mathrm{Li}_{1-\beta} \mathrm{FePO}_{4}$ with $\alpha, \beta \approx 0$. Both end-members are orthorhombic materials, so the anisotropic transformation strain has three independent components. The extreme behavior displayed by $\mathrm{Li}_{X} \mathrm{FePO}_{4}$ is also unusual among ion-intercalation materials.

Intermediate cases are more common, such as are encountered in spinel $\mathrm{Li}_{X} \mathrm{Mn}_{2} \mathrm{O}_{4}$, shown in panel (c), and layered $\mathrm{Li}_{X} \mathrm{CoO}_{2}$, shown in panel (d). For electrochemical cycling in the composition region $0 \leq X \leq 1$, (where the electrode voltage is $\sim 4 \mathrm{~V}$ vs. $\left.\mathrm{Li}^{+} / \mathrm{Li}\right), \mathrm{Li}_{X} \mathrm{Mn}_{2} \mathrm{O}_{4}$ is cubic throughout, but there is complex-phase behavior, with two regions of solid solubility for $0.5 \leq X \leq 1$ and $0.2 \leq X \leq 0.25$ separated by a first-order phase transformation for compositions $0.25 \leq X \leq 0.5$ [142]. The two coexisting cubic phases have lattice parameters which differ by $\sim 1.2 \%$. At higher lithium-contents $(1 \leq X \leq 2)$ this material undergoes a first-order phase transformation to a tetragonally distorted spinel with composition $\mathrm{Li}_{2} \mathrm{Mn}_{2} \mathrm{O}_{4}$. In $\mathrm{Li}_{X} \mathrm{CoO}_{2}$, there is also complex phase-behavior with regions of solid-solubility separated by a miscibility gap. In
Fig. 7 Examples of the different possible variations in lattice parameters of Li-storage compounds. Examples shown are (a) cubic $\mathrm{Li}_{X} \mathrm{TiS}_{2}[140]$, (b) $\mathrm{Li}_{X} \mathrm{FePO}_{4}$ [141], (c) $\mathrm{Li}_{X} \mathrm{Mn}_{2} \mathrm{O}_{4}$ [142], and (d) $\mathrm{Li}_{X} \mathrm{CoO}_{2}$. [143]. Subfigure (a) reprinted from [140] with permission from Elsevier. Subfigures (b)-(d) reproduced by permission of The Electrochemical Society (a)

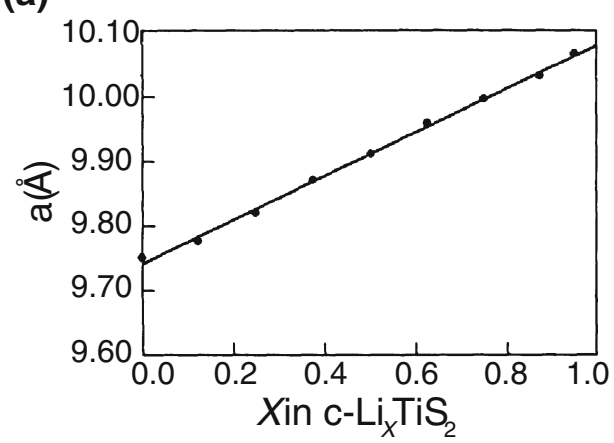

(c)

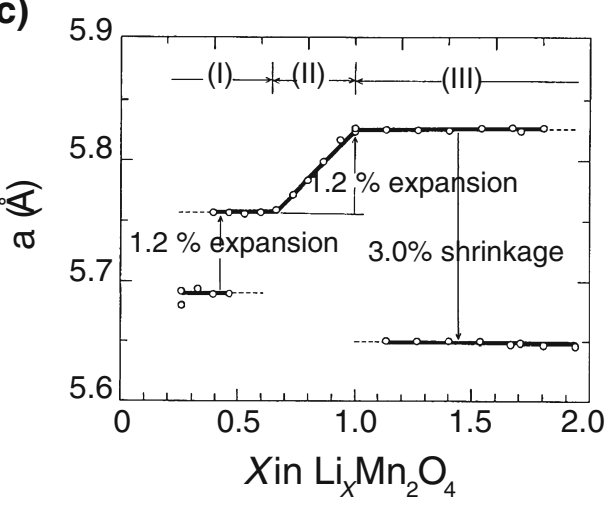

(b)

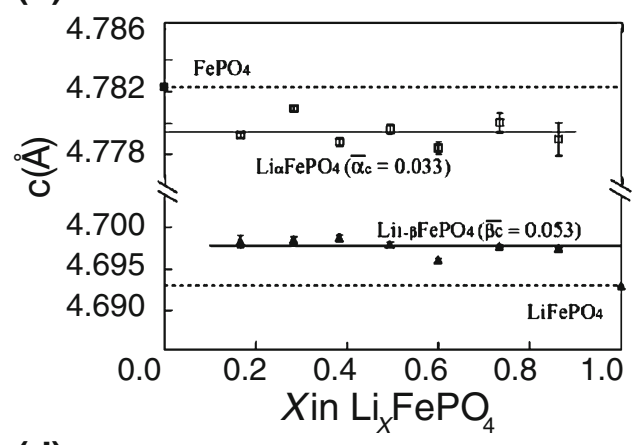

(d)

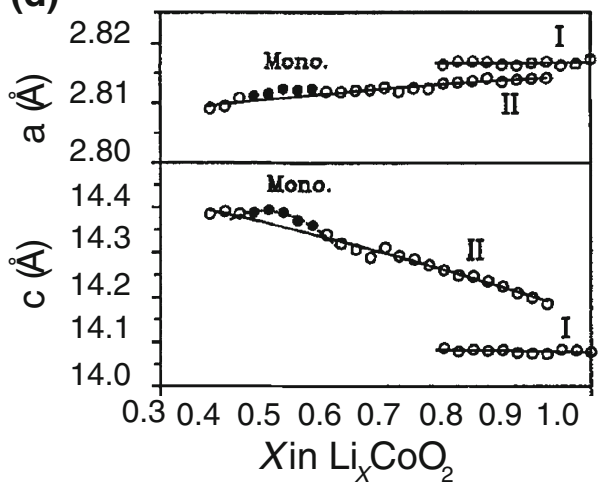


this layered compound, the shape change is anisotropic, and the partial molar volume of lithium is negative [143].

In all of these cases, the composition-induced stressfree strains are beyond the failure strains of most brittle materials. As a result, there have been numerous observations of mechanical deformation and battery peformance degradation associated with these shape changes [144153]. This electrochemical-cycling-induced fracture has been termed "electrochemical shock," by analogy to thermal shock of brittle materials [13]. In ion-intercalation materials, including those used as lithium-storage materials, there are three distinct mechanisms for electrochemical shock: 1) concentration-gradient stresses which arise during fast cycling, 2) two-phase coherency stresses which arise during first-order phase-transformations, and 3) intergranular compatibility stresses in anisotropic polycrystalline materials. While concentration-gradient stresses develop in proportion to the applied electrochemical cycling rate (C-ratedependent), coherency and compatibility stresses persist even to arbitrarily slow cycling rates and may be considered C-rate-independent. One way of summarizing these mechanisms and the microstructure design criteria resulting from them is with an electrochemical shock map [13, 14], which graphically summarizes the microstructure and duty cycle combinations which avert electrochemical shock. Figure 8 shows these maps for the mechanisms discussed above. In such a map, the lines are drawn for a constant value of fracture toughness $K_{\text {Ic }}$, a measure of a material's resistance to catastrophic crack growth. On the electrochemical shock map, combinations of crystallite size and C-rate lying above and to the right of the line are subject to electrochemical shock and fracture failure, while combinations lying below and to the left of the line are not.

In a given material, the potentially operative electrochemical shock mechanisms are determined by the phasebehavior with respect to composition and the crystal symmetry of the intercalation compound. Both of these materials properties are evident from the compositiondependent lattice parameters. Thus, $\mathrm{Li}_{X} \mathrm{FePO}_{4}, \mathrm{Li}_{X} \mathrm{Mn}_{2} \mathrm{O}_{4}$, and $\mathrm{Li}_{X} \mathrm{CoO}_{2}$ are all susceptible to coherency-stress fracture due to the first-order phase transformations, and $\mathrm{Li}_{X} \mathrm{FePO}_{4}$ and $\mathrm{Li}_{X} \mathrm{CoO}_{2}$ are both susceptible to anistropyinduced microfracture if they are prepared in a polycrystalline form. To summarize, most lithium-storage compounds are either non-cubic or undergo first-order phase transformations during electrochemical cycling; therefore, C-rate-independent electrochemical shock mechanisms are ubiquitous.

To design new, electrochemical shock resistant ionintercalation materials, it is important to note that the Crate-independent electrochemical shock mechanisms are not strongly sensitive to the total volume change; these mechanisms are sensitive to the misfit strain through a first-order phase-transformation and the principal shear component of
Fig. 8 Schematic electrochemical shock maps illustrating the different possible combinations of

C-Rate-dependent and C-Rateindependent electrochemical shock mechanisms. Modified from [14] and reproduced by permission of The Royal Society of Chemistry

\section{Solid Solution}
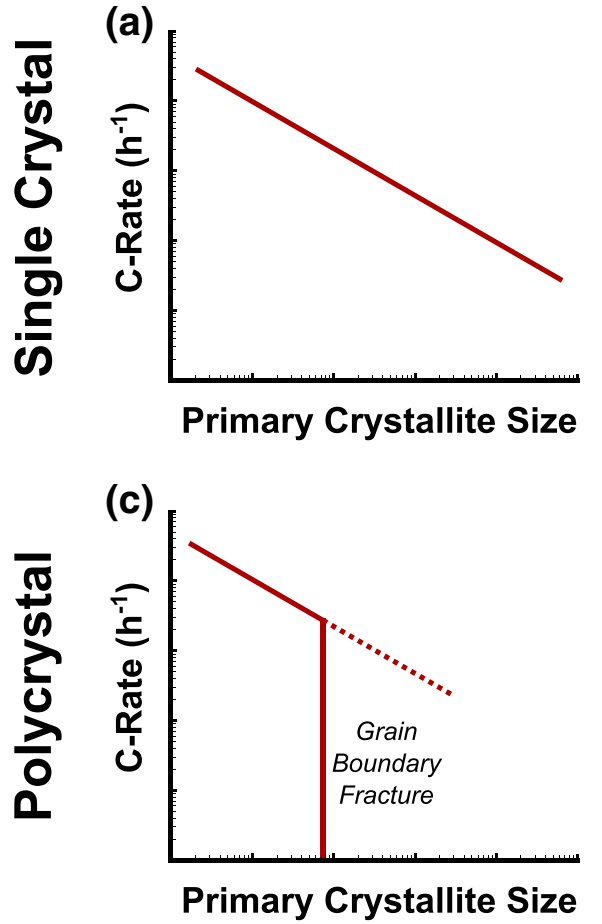

Phase Transformation
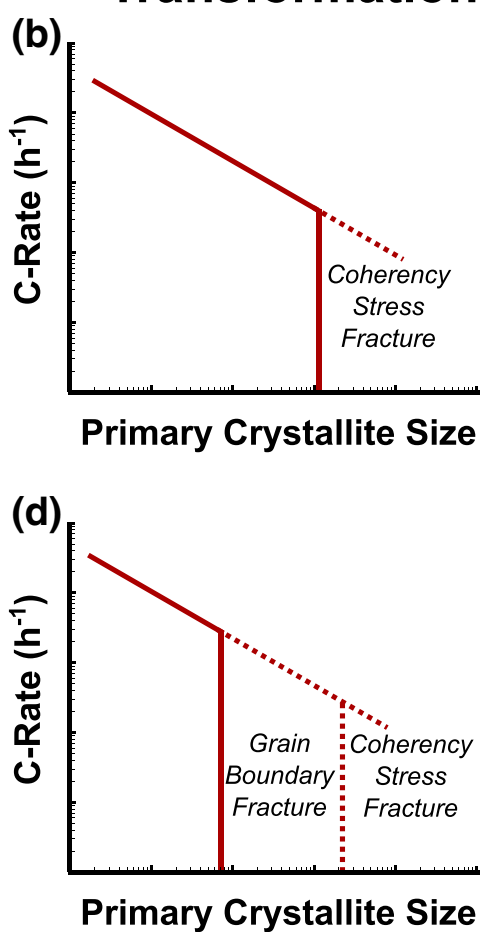
the shape change. Thus, to avoid electrochemical shock in the commercialized classes of $\mathrm{Li}$-storage compounds, it is not necessary to design materials with minimized volume change. New materials with reduced miscibility gaps, reduced misfit strains, and more isotropic shape changes can dramatically improve the mechanical reliability of ionintercalation materials.

Predictive design tools like the electrochemical shock map need to be developed for the relevant phenomena that are found in materials for SOFCs. Specifically, tools that can be used to predict failure regimes such as plastic deformation or brittle cracking, or that can be used to identify conditions of enhanced performance in either charge transport or reactivity would allow device designers to find those materials that have the best combinations of mechanical stability and electrochemical performance.

In order to develop such tools, and to fully understand how thermochemical expansion may either enhance or degrade mechanical durability and electrochemical performance, data from in situ measurement, as well as computational models must be generated. Huang et al. studied the Young's modulus and fracture toughness of $(\mathrm{Sr}, \mathrm{Y}) \mathrm{TiO}_{3}$ in oxidizing and reducing conditions over a range of temperatures using both the resonance method and ring on ring testing and determined that the fracture toughness doubled between room temperature and $900{ }^{\circ} \mathrm{C}$ [154]. As mentioned, Kawada et al. made great strides in in situ measurement of elastic properties of such compounds, reporting Young's moduli, shear moduli, and Poisson's ratios of such diverse materials as GDC, YSZ, $\mathrm{La}_{0.9} \mathrm{Sr}_{0.1} \mathrm{Ga}_{0.8} \mathrm{Mg}_{0.2} \mathrm{O}_{3-\delta}$, and $\mathrm{La}_{0.6} \mathrm{Sr}_{0.4} \mathrm{Co}_{1-y} \mathrm{Fe}_{y} \mathrm{O}_{3-\delta}$ [80-82]. They found that for GDC, the Young's modulus is well-predicted at high temperatures across a range of oxygen partial pressures by use of a modified Lennard-Jones potential that accounts for both changing lattice parameters and nonstoichiometry levels [81]. For LSCF6428 and LSC, Kimura et al. found that the Young's modulus exhibits a minimum at intermediate temperatures [80]. This minimum occurs at the rhombohedral to cubic phase transition temperature of LSCF, a transition temperature that appears to decrease in LSCF6428 with decreasing oxygen partial pressure, corresponding to increased oxygen vacancy concentrations. Within the same group, Kushi et al. also observed such minima for doped zirconia electrolyte materials [82]. Giraud and Canel also observed a minimum in Young's modulus for YSZ as measured by the impulse excitation technique over a range of temperatures [155]. As has been observed for LIBs, controlling phase transitions such as this could be very important in developing fuel cells that can be cycled repeatedly without suffering from mechanical failure.

Once the dependence of the mechanical properties of materials for fuel cells on environmental conditions has been characterized fully for model systems, the interactions of these properties with engineered strain and charge transport will need to be determined. It will then be possible to combine such data with modeling of actual devices to predict those designs which take advantage of electrochemo-mechanical coupling in these materials to enhance performance while maintaining or even improving durability. Thus, we next consider coupling among mechanical strain, species segregation, and surface reactivity.

\section{Strain, segregation, and reactivity}

Given the close association between chemistry and mechanics in ionically conductive ceramics for SOFCs and LIBs, it is reasonable to expect that strain may be used to influence chemistry just as chemical composition gradients may produce strain in these materials. If such coupling could be understood and controlled, this modulation would provide a handle for controlling surface reactivity, a property fundamental to materials for both SOFCs and LIBs. Indeed, investigation into the influence of strain on the chemistry and reactivity of ceramic surfaces forms a rich area of research that encompasses novel in situ characterization techniques and advanced computational methods.

We will use the oxygen reduction reaction (ORR) that occurs at SOFC cathode surfaces as an example to discuss the complicated relationship between strain state and surface activity. The direct correlation between strain and the ORR has been widely studied and well-understood for metal catalysts, based on the d-band model to describe the reactivity to ORR [156]. However, this correlation in oxides has only recently become clear, largely due to the increased complexity of oxides as compared to metals. For example, there is currently no well-accepted electronic structure descriptor for surface activity on oxide surfaces. For transition metal catalysts, the transition metal d-band structure is a widely accepted surface reactivity descriptor [157]. Hence, the impact of strain on reactivity can be well-understood by observing its impact on the d-band structure of the metal catalyst $[158,159]$. Recent experimental and computational work has indicated that the d-band model is not applicable to oxides [160]. Other descriptors, such as $\mathrm{e}_{g}$-state occupancy, the covalency of the transition metal-oxygen bond for low-temperature ORR activity in water, the $\mathrm{O} 2 \mathrm{p}$ band center energy, and the minority electronic carrier density in the conduction band of the material have been proposed [160 162]. However, none of these seem to work for oxides in general. Thus, there is a great challenge for researchers to correlate the strain state of a material to its surface ORR activity. Furthermore, cation segregation at surfaces is generally observed in SOFC cathode oxides. These segregation layers can be very different from the bulk materials and may 
have a severe impact on the surface ORR activity. In this section, we will first give experimental evidence that shows directly the correlation between strain and surface ORR activity. Then, we will introduce theoretical studies on the role of strain in determining the ORR activity at the surface. Finally, strain effects on other cathode materials properties that determine ORR activity will be introduced.

To understand the mechanism by which strain impacts the ORR activity, it is necessary to understand the impact of strain on the elementary steps of the reaction, including oxygen adsorption, dissociation, incorporation, and diffusion. For investigating the effects of strain on the performance of the SOFC cathode, Sr doped $\mathrm{LaCoO}_{3}$ has drawn significant attention, both experimentally and computationally. Because of the ability to simplify the model system, firstprinciples based calculations are particularly suitable for identifying the strain impact on each reaction step [163]. Han and Yildiz studied how strain affected oxygen diffusion on the (100) surface of $\mathrm{LaCoO}_{3}(\mathrm{LaCO}$, to distinguish from the $\mathrm{LCO}$ abbreviation of $\mathrm{LiCoO}_{2}$ in LIBs) using DFT $+\mathrm{U}$ calculations [164]. They found that the migration of oxygen vacancies and adsorbed oxygen were the key ratelimiting steps governing the overall oxygen incorporation kinetics. Planar tensile strain was predicted to reduce the oxygen vacancy formation energy and the oxygen vacancy migration barrier and strengthen oxygen adsorption on the $\mathrm{LaCoO}(001)$ surface $[164,165]$. These results suggest formation of a greater concentration of oxygen vacancies as active sites, an enhanced mobility of these sites on the surface, and a greater surface coverage of oxygen. Both of these factors accelerate ORR kinetics. On the other hand, tensile strain was shown to simultaneously decrease the mobility of adsorbed oxygen atoms. From this we can see that lattice strain can cause competing effects on the ORR activity. By evaluating the collective kinetics of the surface reactions, Han and Yildiz identified the existence of an optimal strain state of $3 \%$ planar tensile strain. The explanation of these trends is as follows: When tensile strain is small, elastic stretching of the Co-O bond facilitates oxygen vacancy formation as well as adsorption. At very high strain states, the local relaxations increase the $\mathrm{Co}-\mathrm{O}$ bond strength, leading to trapping of lattice oxygen. As a result, the oxygen vacancy formation energy increases, and the chemisorption of oxygen is inhibited. Furthermore, as strain increases, spin state transitions must also be taken into account. Collectively, these results showed that the surface ORR activity is not necessarily monotonically increasing or decreasing as a function of strain state. Note that Kushima et al. had previously reported the existence of a similarly optimal strain state for oxygen ionic diffusion in YSZ, based on similar calculations for that common SOFC electrolyte [90].

Electronic structure also plays a major role in influencing surface oxygen reduction reactivity, as has been illustrated by examples in several oxides [55, 160-162]. Using in situ STM/S, Yildiz et al. conducted a series of studies on the surface electronic structure of tensile and compressive-strained ( $\mathrm{La}, \mathrm{Sr}) \mathrm{CoO}_{3}$ and $(\mathrm{La}, \mathrm{Sr}) \mathrm{MnO}_{3}$ at high temperature in an oxygen environment $[45,53]$. They found that the tensile-strained film showed a higher density of states near the Fermi level at high temperature compared with compressive-strained films. This difference could lead to easier charge transfer during the ORR reaction for the tensile-strained surfaces. High temperature XPS results and DFT calculations support that tensile strain could cause such a difference in electronic structure by causing easier formation of oxygen vacancies near the surface $[45,53]$. Lussier et al. grew $\mathrm{La}_{2 / 3} \mathrm{Ca}_{1 / 3} \mathrm{MnO}_{3}$ thin films with desired induced strain by depositing the films on $\mathrm{SrTiO}_{3}(100)(\mathrm{STO}), \mathrm{SrRuO}_{3}(100)(\mathrm{SRO}), \mathrm{LaAlO}_{3}(100)$ (LAO), and $\mathrm{NdGaO}_{3}(100)$ (NGO) [166]. The strain state ranged from tensile to compressive to negligible strain. The electronic structures were probed by X-ray absorption spectroscopy of the $\mathrm{Mn} \mathrm{L}_{2,3}$ edge. Both compressive and tensile strain were found to modify the relative $\mathrm{La}$ and $\mathrm{Sr}$ content near the interface and lead to changes in the valence state of the Mn cation. Such changes were expected to impact oxygen diffusion across the interface. Finally, Yamada et al. exposed $\mathrm{SrFeO}_{3}$ films to extreme oxidizing conditions and found that the one with large tensile strain remained a semiconductor while the one with smaller tensile strain transitioned into being a metal [167].

The first work that directly probed the effect of lattice strain on the oxygen exchange kinetics at the collective level was that of Kubicek and Cai et al [2]. Those researchers obtained epitaxial LSC thin films with tensile and compressive strain by growing $\mathrm{LSC}$ on top of $\mathrm{SrTiO}_{3}$ (STO, tensile) and $\mathrm{LaAlO}_{3}$ (LAO, compressive) substrates. Using ${ }^{18} \mathrm{O}$ isotope exchange depth profiling with ToF-SIMS, they measured the oxygen tracer exchange coefficient $k^{*}$ and tracer diffusion coefficient $D^{*}$ on the surfaces of these films, at temperatures ranging from $280{ }^{\circ} \mathrm{C}$ to $475{ }^{\circ} \mathrm{C}$. They found that the surface exchange and diffusion for the film with tensile strain were about four times and 10 times faster than the film under compressive strain, respectively. These results confirmed the earlier predictions at the elementary reaction level that tensile lattice strain accelerates oxygen reduction and diffusion on the LSC (and LSM), reported by several computational studies on the same material systems $[45,53]$. Consistent with this, $\mathrm{La} \mathrm{O}^{\prime}$ et al. found also that epitaxial films of LSC on a GDC/YSZ substrate showed enhanced chemical surface exchange kinetics [168]. However, the effect of strain was not clearly demonstrated or explained. On another material system, Burriel et al. investigated epitaxially grown $\mathrm{La}_{2} \mathrm{NiO}_{4}$ (c-axis perpendicular to the substrate surface) on $\mathrm{SrTiO}_{3}(100)$ and $\mathrm{NdGaO}_{3}$ (110) with thicknesses from $33 \mathrm{~nm}$ to $370 \mathrm{~nm}$ 
[57], with seemingly contradictory results to those shown on the strained LSC films. While the $\mathrm{La}_{2} \mathrm{NiO}_{4}$ films grown on STO were compressively strained, those grown on $\mathrm{NdGaO}_{3}$ were under tensile strain. XRD results further showed that both compressive and tensile strain decreased with increasing thickness. Using an isotope exchange technique, those researchers determined the anisotropic tracer diffusion and surface exchange coefficients of films with different strain states, and found no difference between the films on $\mathrm{NdGaO}_{3}$ and those on $\mathrm{SrTiO}_{3}$. Furthermore, the tracer diffusion coefficients along both the c-axis and the $a-b$ plane were found to decrease with decreasing film thickness, i.e., with increasing strain. These results indicate that for $\mathrm{LaNiO}_{4}$ films, both tensile and compressive strain has a similarly negative impact on oxygen diffusion, but have no influence on oxygen surface exchange. The fact that $\mathrm{La}_{2} \mathrm{NiO}_{4}$ is not a perovskite like LSC and the oxygen exchange and diffusion mechanisms are not based on oxygen vacancies may be the reason for the different strain response of $\mathrm{La}_{2} \mathrm{NiO}_{4}$ compared to that of LSC films summarized above.

Cation segregation at/near oxide surfaces is a widely observed phenomenon that occurs for perovskite or related materials such as STO, LSM, and STF [169-173]. Such deviations from the bulk nominal composition and phase can have great impact on ORR reactivity. For example, as shown in Fig. 9, experimental results showed that $\mathrm{SrO}$ segregation on Fe-substituted STO surfaces can strongly degrade the ORR activity by creating a blocking layer for

(a)

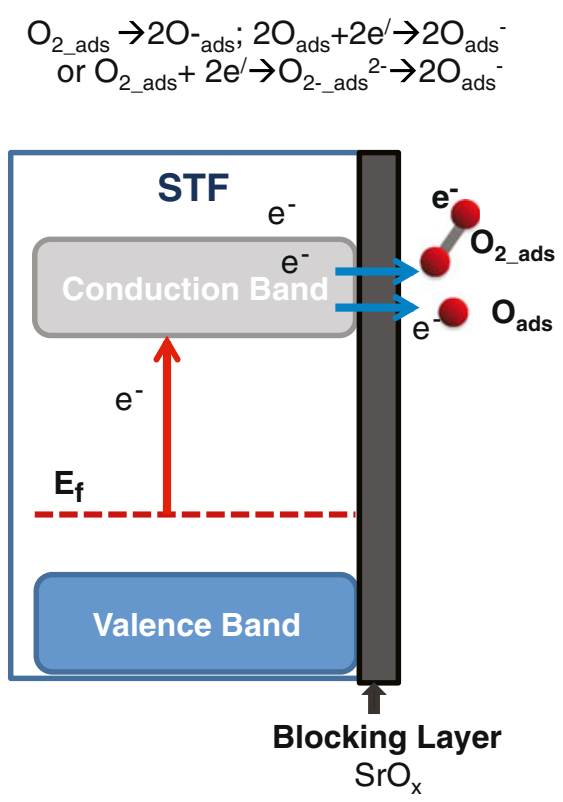

Fig. 9 Segregation of cations to the surface of $\mathrm{SrTi}_{1-x} \mathrm{Fe}_{x} \mathrm{O}_{3}$ degrades oxygen reduction reactivity by two possible mechanisms. (a) A blocking layer of $\mathrm{SrO}_{x}$ forms on the surface of STF and acts as a barrier to charge or oxygen transfer. (b) A downshift in the $\mathrm{O} 2 \mathrm{p}$ charge transfer processes and decreasing the concentration of oxygen vacancies near the surface [55, 173]. A similar deteriorating impact of $\mathrm{Sr}$ segregation on ORR activity was reported also for LSC and LSM [174-176]. Therefore, to understand how strain impacts the ORR activity, one needs to understand the influence of strain also on the surface cation chemistry and composition as an outcome of segregation. Cai et al. found that LSC films with tensile strain had more $\mathrm{Sr}$ segregation to the surface compared to those with compressive strain [45]. Jalili et al. observed a similar behavior in LSM films [53]. Estradé et al. used EELS to map composition and electronic states in epitaxial $\mathrm{La}_{2 / 3} \mathrm{Ca}_{1 / 3} \mathrm{MnO}_{3}$ films grown on $\mathrm{SrTiO}_{3}$ (001) and (110) substrates [22]. While the cationic composition and valence state of $\mathrm{Mn}$ ions stayed the same across the film thickness on the relaxed film (the one grown on (110)), the $\mathrm{Ca} / \mathrm{La}$ ratio gradually changed across the tensile-strained films; for the fully strained film (grown on (001)), the ratio was La-rich at the film/substrate interface, where tensile strain was also greater, and La-depleted at the free surface. Strain dependency of cation composition at the surface can arise from the elastic and electrostatic interactions of the cations with the host lattice [177]. All of these results point to the possibility of controlling the surface chemistry by controlling the strain state of the film, and thereby changing the surface ORR activities.

It is clear, then, that the chemomechanical coupling of oxides for SOFCs can be exploited to adjust surface chemistry and reactivity. It may be that a similar potential exists to

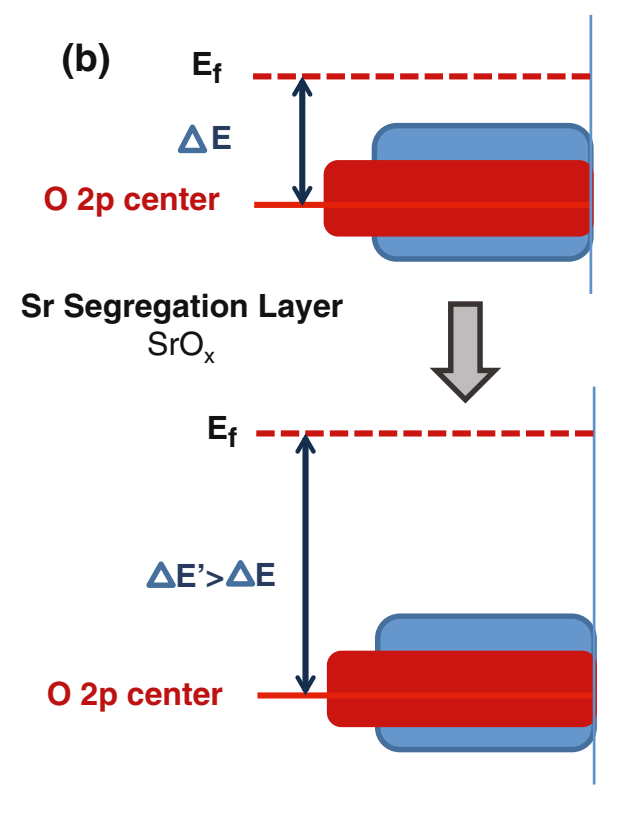

position results in fewer oxygen vacancies available at the surface for oxygen adsorption and incorporation reactions. Reproduced from [55] by permission of the Royal Society of Chemistry 
change surface reactivity by engineering strain (or the conjugate stress) within or among lithium intercalation compounds. Sethuraman et al. investigated the stress-potential coupling in lithiated silicon through experimental measurements of changes in substrate curvature during electrochemical lithiation and delithiation [178]. They found that the strength of the coupling was on the order of $100 \mathrm{mV} / \mathrm{GPa}$, corresponding to a major contribution to energy dissipation during charge/discharge cycles that resulted from plastic flow associated with stresses arising within the film. In comparison, the stress-potential coupling in yttria stabilized zirconia has been measured to be $\sim 30 \mathrm{mV} / \mathrm{GPa}$ [179]. Sethuraman et al. further suggested that device designs that minimized stress formation during cycling would have improved charge/discharge capacities. Building off of this work, Bower et al. developed an extensive analytical model of a simple layered LIB based on the field equations for coupled stress, diffusion, electric fields, and electrochemical reactions [180]. The model was able to reproduce most features of the potential and stress cycles originally observed by Sethuraman et al. quite successfully, confirming the energy dissipation resulting from stress-potential coupling.

While the potential coupling can be either positive or negative (depending on the sign of the partial molar volume), the effect of chemomechanical coupling also provides a driving force for ion transport. This driving force is proportional to the gradient of hydrostatic stress for an isotropic system, and this chemomechanical coupling always serves to enhance transport relative to an unstressed system. The magnitude of the the thermodynamic driving force for transport is always positive, depending on the square of the characteristic volume of the process, $\Omega$. Thus, a large applied tensile or compressive stress can be expected to change the charge and discharge capacities of lithium storage compounds, but such engineered stress must compete with stresses arising from the natural volume changes that these materials undergo during lithiation and delithiation. Next, we consider how strain can modulate chemistry and conductivity.

\section{Strain, chemistry, and conductivity}

Interest in the electro-chemo-mechanical coupling behavior of nonstoichiometric materials for energy conversion is strongly motivated by the potential to enhance material performance by exploiting this coupling. A lot of excitement has been generated recently over the potential to use engineered strain to improve the ionic conductivity of electrodes and electrolytes for fuel cells. One major theory about the mechanism of this enhancement is that of the "activation volume" [181]. Generally speaking, the rate constant $k$ of a typical process will show Arrhenius behavior of the type described by Eq. 6, where $\Delta G^{\ddagger}$ is the Gibb's free energy of activation for the process, which can be broken into an entropic contribution, $-T \Delta S^{\ddagger}$, a contribution from the elastic strain energy of activation (where $\epsilon_{i j}^{\ddagger}$ is the activation strain of the process, and $\sigma_{i j}$ is the stress) and a contribution from the internal energy, $\Delta U^{\ddagger}$.

$$
\begin{aligned}
k & =k_{0} \exp \left(\frac{-\Delta G^{\ddagger}}{R T}\right) \\
& =k_{0} \exp \left(\frac{\Delta S^{\ddagger}}{R}\right) \exp \left(\frac{\epsilon_{i j}^{\ddagger} \sigma_{i j} \Omega}{R T}\right) \exp \left(\frac{-\Delta U^{\ddagger}}{R T}\right)
\end{aligned}
$$

Such a rate law could be applied to the process of vacancy migration to a neighboring lattice site. In the simplified case of hydrostatic stress, the rate law then becomes Eq. 7 where $P$ is the pressure and $\Omega^{\ddagger}$ is the activation volume.

$k=k_{0} \exp \left(\frac{\Delta S^{\ddagger}}{R}\right) \exp \left(\frac{-P \Omega^{\ddagger}}{R T}\right) \exp \left(\frac{-\Delta U^{\ddagger}}{R T}\right)$

If the activation entropy and internal energy remain insensitive to pressure, then the activation volume can be determined from the pressure dependence of the rate, according to Eq. 8 .

$\Omega^{\ddagger}=-R T\left(\frac{\partial \log k}{\partial P}\right)$

Thus, the application of a stress to the material will cause a change in the rate of vacancy migration corresponding to a change in the activation free energy of the process. In general it has been hypothesized that a tensile strain will lower the vacancy migration energy by decreasing the activation free energy, and therefore enhance the rate of vacancy migration, corresponding to an increase in ionic conductivity. The reverse effect is expected for a compressive strain.

With the advent of thin film growth techniques, precise control of thin film thickness and interfaces is now readily achieved, enabling the study of strain effects on ionic conductivity through epitaxially induced interfacial strain. Sata et al. significantly improved the ionic conductivity of the $\mathrm{CaF}_{2} / \mathrm{BaF}_{2}$ superlattice by reducing the thickness of each layer to less than the width of the space charge region [182]. Kosacki et al. studied the nanoscale effect of strain on highly textured YSZ thin films and found that the ionic conductivity was enhanced by one order of magnitude when the film thickness was decreased to $15 \mathrm{~nm}$ [183].

Garcia-Barriocanal et al. reported an eight order of magnitude increase of ionic conductivity relative to bulk YSZ using a trilayer structure of $\mathrm{SrTiO}_{3}(10 \mathrm{~nm}) / \mathrm{YSZ}(1 \mathrm{~nm}) /$ 
$\mathrm{SrTiO}_{3}(10 \mathrm{~nm})$ [184]. There has been a great deal of debate about the coupling between strain and conductivity in the wake of that 2008 publication, including debate about the cause of the observed conductance [185]. Cavallaro et al. found through a combination of IS and SIMS enabled oxygen isotope exchange depth profiling that the observed enhancement could instead be attributable to a strong electronic contribution [186]. DFT and kMC simulations by Kushima and Yildiz of the effect of biaxial lattice strain on YSZ found that the maximum enhancement of the oxygen diffusivity for that system was 3-4 orders of magnitude at $4 \%$ tensile strain at $400 \mathrm{~K}$; this effect decreased to within an order of magnitude at $1000 \mathrm{~K}$ [90]. These simulations also found that the change in oxygen diffusivity with strain was due to changes in the vacancy migration energy barrier, influenced by the competing effects of increased migration space and increased oxygen-cation bond strength.

Schichtel et al. used a combination of theoretical considerations and experimental data to investigate the effect of elastic strain on ionic conductivity at coherent interfaces between YSZ and insulating oxides [187]. Figure 10 illustrates their result that the conductivity was enhanced by less than a factor of two at $3 \%$ and $4 \%$ lattice mismatch, though the exact strain state of the films was not reported. Furthermore, these authors calculated that the maximum enhancement in interfacial conductivity that could be expected from a tensile strain was only about 2.5 orders of magnitude, in conflict with the enhancement reported by Garcia-Barriocanal. In related work, Aydin et al. determined the ${ }^{18} \mathrm{O}$-tracer diffusion coefficient for $\mathrm{YSZ} / \mathrm{Y}_{2} \mathrm{O}_{3}$ multilayers and found that the diffusivity increased by a factor of two compared to the bulk when the thickness of each layer was decreased from 45

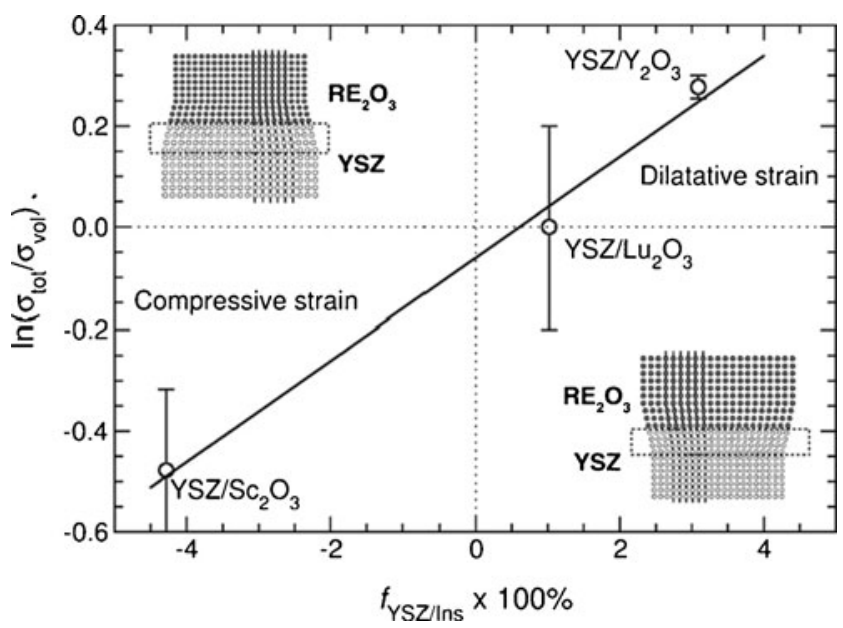

Fig. 10 Yttria-stabilized zirconia exhibits ionic conductivity that some researchers have found to correlate with elastic strain at coherent interfaces with insulating oxides. Reproduced from Ref [187] with permission of the PCCP Owner Societies to $12 \mathrm{~nm}$ [188]. Pergolesi et al. fabricated $\mathrm{YSZ} / \mathrm{CeO}_{2}$ multilayer samples with varying numbers of heterointerfaces with minimal interfacial dislocation densities [189]. Electrochemical impedance spectroscopy (EIS) and secondary ion mass spectroscopy (SIMS) found no detectable change in ionic conductivity as a result of tensile lattice distortion at the interfaces. This result was consistent with the findings of Sayle et al. through atomistic simulation [190]. Although Pergolesi et al. hypothesized that enhanced ionic transport observed in other studies was likely the result of conductivity paths along dislocation lines or grain boundaries, $\mathrm{Li}$ et al. fabricated multilayered $\mathrm{YSZ} / \mathrm{Gd}_{2} \mathrm{Zr}_{2} \mathrm{O}_{7}$ films with coherent, dislocation free interfaces with $3 \%$ tensile strain in the YSZ layers that displayed a two order of magnitude increase in ionic conductivity relative to bulk YSZ [191]. These hypotheses and experimental observations can be compared to the computational predictions of mechanism by Kushima [90] for YSZ/MgO.

As summarized in Table 1, these collective studies have found conflicting evidence for the effect of tensile strain on ionic conductivity in YSZ, ranging from no effect at all to an 8 order-of-magnitude enhancement. This confusion can, in part, be explained by the factors introduced by interfaces in multilayer structures in addition to strain, including dislocations, grain boundaries, and space charge regions. Furthermore, in some cases it is possible that contributions from electronic or protonic conductivity introduced artifacts into the measurements [186, 192]. It is clear that great consideration must be taken in experimental designs for studying strain effects on conductivity, including careful choice of insulating materials and close attention to local defect structures at interfaces. Additionally, there has been little exploration of this effect for materials other than YSZ. While further systematic experimental studies of this effect for YSZ are called for, there remain many ionic conductors for which such an effect may exist and could be utilized to enhance cathode, electrolyte, or anode performance. The only experimentally demonstrated effect of lattice strain on oxygen ion conduction in a different material thus far is in the LSC films strained in tension and compression; in those studies, tensile planar strain accelerated oxygen diffusion by ten times compared to the compressive strain state [2]. This result is encouraging, as it suggests that strained perovskite oxide films could accelerate oxygen diffusion in the cathode of SOFCs.

Although connections between chemical-expansioninduced strain and electrode damage have been extensively studied in the field of lithium ion batteries, very little work has been done investigating the relationships between strain or stress and lithium diffusivity. Choi and Pyun found that increased intercalation-induced stress gradients within 
Table 1 Summary of literature reports of ionic conductivity of strained interfaces

\begin{tabular}{|c|c|c|c|c|}
\hline Material & Geometry & $\mathrm{T}(\mathrm{K})$ & Relative increase in ionic conductivity & Reference \\
\hline YSZ/STO & Multilayer & $357-531$ & $10^{8}$ relative to bulk YSZ & [184] \\
\hline $\mathrm{CaF}_{2} / \mathrm{BaF}_{2}$ & Multilayer & $373-773$ & $\begin{array}{l}10^{3} \text { relative to bulk } \mathrm{CaF}_{2} \\
10^{2} \text { relative to bulk } \mathrm{BaF}_{2}\end{array}$ & [182] \\
\hline $\begin{array}{l}\mathrm{Ce}_{0.8} \mathrm{Sm}_{0.2} \mathrm{O}_{2-\delta} \\
(\mathrm{SDC}) / \mathrm{YSZ}\end{array}$ & Multilayer & $673-1073$ & $\begin{array}{l}10^{1} \text { relative to SDC and YSZ thin films } \\
10^{2} \text { relative to bulk SDC pellets }\end{array}$ & [193] \\
\hline $\mathrm{YSZ} / \mathrm{Y}_{2} \mathrm{O}_{3}$ & Multilayer & $623-973$ & $10^{1}$ relative to $\mathrm{YSZ}$ & {$[194]$} \\
\hline YSZ/STO & Multilayer & $373-773$ & $\begin{array}{l}\text { No significant enhancement in oxygen diffusion } \\
10^{5} \text { enhancement in electrical conductivity } \\
\text { relative to } \mathrm{YSZ} / \mathrm{Al}_{2} \mathrm{O}_{3}\end{array}$ & {$[186]$} \\
\hline $\begin{array}{l}\text { YSZ on } \mathrm{MgO} \\
\text { YSZ on STO }\end{array}$ & Epitaxial thin film & $423-773$ & $10^{3}$ relative to bulk YSZ & [195] \\
\hline $\mathrm{Ce}_{0.9} \mathrm{Gd}_{0.1} \mathrm{O}_{2-\delta}$ & Epitaxial thin film & $723-1123$ & $\begin{array}{l}10^{1} \text { relative to } \\
\mathrm{MgO}(001) / \mathrm{CGO}_{250 \mathrm{~nm}} \text { (polycrystalline) }\end{array}$ & [196] \\
\hline $\begin{array}{l}\text { LSC on STO } \\
\text { LSC on LAO }\end{array}$ & Epitaxial thin film & $553-748$ & $\begin{array}{l}10^{1} \text { enhancement in oxygen diffusivity for } 1.4 \% \\
\text { tensile strain relative to } 1.5 \% \text { compressive strain }\end{array}$ & {$[2]$} \\
\hline YSZ & $\begin{array}{l}\text { Simulated lattice } \\
\text { Biaxial strain }\end{array}$ & $400-1000$ & $\begin{array}{l}10^{3.5} \text { at } 1000 \mathrm{~K} \text { and } 10^{1} \text { at } 400 \mathrm{~K} \\
\text { relative to unstrained YSZ }\end{array}$ & {$[90]$} \\
\hline $\mathrm{CeO}_{2}$ & $\begin{array}{l}\text { Simulated lattice } \\
\text { Biaxial strain } \\
\text { Isotropic strain }\end{array}$ & $500 \mathrm{~K}$ & $10^{4}$ relative to unstrained $\mathrm{CeO}_{2}$ & [181] \\
\hline $\begin{array}{l}\mathrm{YSZ} / \mathrm{Y}_{2} \mathrm{O}_{3} \\
\mathrm{YSZ} / \mathrm{Lu}_{2} \mathrm{O}_{3} \\
\mathrm{YSZ} / \mathrm{Sc}_{2} \mathrm{O}_{3}\end{array}$ & Multilayer & $833 \mathrm{~K}$ & $\begin{array}{l}\text { Measured } \leq 2 \mathrm{x} \text { enhancement } \\
\text { Predicted maximum enhancement } \\
\text { of } 10^{2.5}\end{array}$ & [187] \\
\hline $\mathrm{YSZ} / \mathrm{CeO}_{2}$ & Multilayer & $673-973$ & No detectable change & [189] \\
\hline $\begin{array}{l}\mathrm{YSZ} / \mathrm{Y}_{2} \mathrm{O}_{3} \\
\mathrm{YSZ} / \mathrm{Lu}_{2} \mathrm{O}_{3} \\
\mathrm{YSZ} / \mathrm{Sc}_{2} \mathrm{O}_{3}\end{array}$ & Multilayer & 793 & Factor of 2 relative to bulk YSZ & {$[188]$} \\
\hline $\mathrm{YSZ} / \mathrm{Gd}_{2} \mathrm{O}_{7}$ & Multilayer & $570-750$ & $10^{2}$ relative to bulk YSZ & [191] \\
\hline
\end{tabular}

particles of $\mathrm{LiCoO}_{2-\delta}$ correlated with decreased lithium diffusivity [197]. The nanoscale mapping of regions of enhanced lithium diffusivity performed by Balke et al. identified grains and grain boundaries of enhanced diffusivity with ESM [52]. Such SPM mapping techniques could in principle be used to study diffusivities in thin film structures fabricated to contain engineered strains, and thus elucidate coupling between strain and lithium transport. Investigation of the basic mechanisms of strain-transport coupling in lithium intercalation compounds would likely be most expedient if model systems based on thin films are used. Computational studies similar to those undertaken by Kushima and Yildiz could likewise elucidate such phenomena [90]. In general, the potential to exploit the inherent electro-chemo-mechanical coupling of lithium intercalation materials to enhance battery performance represents an area of research that remains largely unexplored.

\section{Summary and Outlook}

In order to improve prediction and duration of fuel cell and battery lifetime, fundamental research is required to first better understand the coupling between electrochemical and mechanical processes. This will guide material selection, materials engineering, and device design toward enhanced conductivity and surface reactivity while also increasing the durability of the active compounds in such devices. As noted above, fuel cells for energy conversion and batteries for energy storage share several common features, and thus several modes of characterization. Both operate under far-from-equilibrium conditions, and both require ion transport that does not result in fracture due to unaccommodated strains within the cathode (or anode and electrolyte) materials. Given the strain gradients within these materials that occur upon operation, exploration of key length scales such as film thickness (in SOFCs) and particle size (in LIBs) 
provides a key means to control the mechanical behavior and also to modulate the reactivity and transport. To this end, advances in both in situ experimental methods and computational models are required and must be advanced beyond equilibrium approaches. Together, these tools will enable us to find appropriate material and device designs to leverage strain and chemomechanical coupling for enhancement of both performance and stability. Ultimately, this perspective that embraces the inherent coupling between electrochemistry and mechanics will help transition these promising platforms to improved and more widespread adoption for energy conversion and storage - and potentially also provide new means to couple the capabilities of each device for novel portable energy sources.

Acknowledgments Support from the U.S. Department of Energy Basic Energy Sciences Division of Materials Sciences and Engineering (J. Vetrano, Program Officer), grant DE-SC0002633 is gratefully acknowledged. This work is also supported in part by the Department of Energy Office of Science Graduate Fellowship Program (DOE SCGF), made possible in part by the American Recovery and Reinvestment Act of 2009, administered by ORISE-ORAU under contract no. DE-AC05-06OR23100. J. Swallow further acknowledges support from the MIT DMSE Salapatas Fellowship. K. J. Van Vliet also acknowledges support from the Presidential Early Career Award in Science and Engineering (PECASE) administered by the U.S. Air Force Office of Scientific Research.

\section{References}

1. A. Aguadero, L. Fawcett, S. Taub, R. Woolley, K.-T. Wu, N. Xu, J.A. Kilner, S.J. Skinner, Materials development for intermediate-temperature solid oxide electrochemical devices. J. Mater. Sci. 47(9), 3925-3948 (2012)

2. M. Kubicek, Z. Cai, W. Ma, B. Yildiz, H. Hutter, J. Fleig, Tensile lattice strain accelerates oxygen surface exchange and diffusion in $\mathrm{La}_{1-x} \mathrm{Sr}_{x} \mathrm{CoO}_{3-\delta}$ thin films. ACS Nano 7, 3276-3286 (2013)

3. D. Marrocchelli, S.R. Bishop, H.L. Tuller, B. Yildiz, Understanding chemical expansion in non-stoichiometric oxides: ceria and zirconia case studies. Adv. Funct. Mater. 22(9), 1958-1965 (2012)

4. H.L. Tuller, S.R. Bishop, D. Chen, Y. Kuru, J.-J. Kim, T.S. Stefanik, Praseodymium doped ceria: model mixed ionic electronic conductor with coupled electrical, optical, mechanical and chemical properties. Solid State Ionics 225, 194-197 (2012)

5. S.B. Adler, Factors governing oxygen reduction in solid oxide fuel cell cathodes. Chem. Rev. 104(10), 4791-4844 (2004)

6. W. Jung, H.L. Tuller, Investigation of cathode behavior of model thin-film $\mathrm{SrTi}_{1-x} \mathrm{Fe}_{x} \mathrm{O}_{3-\delta}(\mathrm{x}=0.35$ and 0.5$)$ mixed ionicelectronic conducting electrodes. J. Electrochem. Soc. 155(11), B1194-B1201 (2008)

7. K.L. Duncan, Y. Wang, S.R. Bishop, F. Ebrahimi, E.D. Wachsman, Role of point defects in the physical properties of fluorite oxides. J. Am. Ceram. Soc. 89(10), 3162-3166 (2006)

8. E.D. Wachsman, K. T. Lee, Lowering the temperature of solid oxide fuel cells. Sci. 334, 935-939 (2011)

9. T. Suzuki, Z. Hasan, Y. Funahashi, T. Yamaguchi, Y. Fujishiro, M. Awano, Impact of anode microstructure on solid oxide fuel cells. Sci. 325, 852-855 (2009)
10. W.H. Woodford, PhD thesis, Massachusetts Institute of Technology (2013)

11. H.L. Tuller, S.R. Bishop, Point defects in oxides: tailoring materials through defect engineering. Annu. Rev. Mater. Res. 41, 369-398 (2011)

12. B.C.H. Steele, A. Heinzel, Materials for fuel-cell technologies. Nature. 414, 345-352 (2001)

13. W.H. Woodford, Y.-M. Chiang, W.C. Carter, "Electrochemical shock" of intercalation electrodes: a fracture mechanics analysis. J Electrochem. Soc. 157, A1052-A1059 (2010)

14. W.H. Woodford, W.C. Carter, Y.-M. Chiang, Design criteria for electrochemical shock resistant battery electrodes. Energy Environ. Sci. 5, 8014-8024 (2012)

15. D. Dijkkamp, T. Venkatesan, X.D. Wu, S.A. Shaheen, N. Jisrawi, Y.H. Min-Lee, W.L. McLean, M. Croft, Preparation of Y-Ba-Cu oxide superconductor thin films using pulsed laser evaporation from high $\mathrm{T}_{c}$ bulk material. Appl. Phys. Lett. 51(8), 619-621 (1987)

16. D.B. Chrisey, G.K. Hubler (eds.), Pulsed Laser Deposition of Thin Films (Wiley, 1994)

17. T. Venkatesan, S.M. Green, Pulsed laser deposition: thin films in a flash. Am. Inst. Phys. 22-24 (1996)

18. D.H. Kim, L. Bi, N.M. Aimon, P. Jiang, G.F. Dionne, C.A. Ross, Combinatorial pulsed laser deposition of $\mathrm{Fe}, \mathrm{Cr}, \mathrm{Mn}$, and NiSubstituted $\mathrm{SrTiO}_{3}$ films on Si substrates. ACS Comb. Sci. 14(3), 179-190 (2012)

19. Y. Kuru, H. Jalili, Z. Cai, B. Yildiz, H.L. Tuller, Direct probing of nanodimensioned oxide multilayers with the aid of focused ion beam milling. Adv. Mater. 23(39), 4543-4548 (2011)

20. A. Ohtomo, D.A. Muller, J.L. Grazul, H.Y. Hwang, Artificial charge-modulation in atomic-scale perovskite titanate superlattices. Nat. 419, 378-380 (2002)

21. J. Chakhalian, J.W. Freeland, H.-U. Habermeier, G. Cristiani, G. Khaliullin, M. van Veenendaal, B. Keimer, Orbital reconstruction and covalent bonding at an oxide interface. Sci. 318, 1114-1117 (2007)

22. S. Estradé, J.M. Rebled, M.G. Walls, F. de la Peña, C. Colliex, R. Córdoba, I.C. Infante, G. Herranz, F. Sánchez, J. Fontcuberta, F. Peiró, Effect of the capping on the local Mn oxidation state in buried (001) and (110) $\mathrm{SrTiO}_{3} / \mathrm{La}_{2 / 3} \mathrm{Ca}_{1 / 3} \mathrm{MnO}_{3}$ interfaces. J. Appl. Phys. 110, 103903 (2011)

23. N. Balke, S. Jesse, Y. Kim, L. Adamczyk, I.N. Ivanov, N.J. Dudney, S.V. Kalinin, Decoupling electrochemical reaction and diffusion processes in ionically-conductive solids on the nanometer scale. ACS Nano 4(12), 7349-7357 (2010)

24. C.W. Bark, P. Sharma, Y. Wang, S.H. Baek, S. Lee, S. Ryu, C.M. Folkman, T.R. Paudel, A. Kumar, S.V. Kalinin, A. Sokolov, E.Y. Tsymbal, M.S. Rzchowski, A. Gruverman, C.B. Eom, Switchable induced polarization in $\mathrm{LaAlO}_{3} / \mathrm{SrTiO}_{3}$ heterostructures. Nano Lett. 12(4), 1765-1771 (2012)

25. A. Kumar, F. Ciucci, A.N. Morozovska, S. V. Kalinin, S. Jesse, Measuring oxygen reduction/evolution reactions on the nanoscale. Nat. Chem. 3(9), 707-713 (2011)

26. M.W. Louie, A. Hightower, S. M. Haile, Nanoscale electrodes by conducting atomic force microscopy: oxygen reduction kinetics at the $\mathrm{Pt} \mid \mathrm{CsHSO}_{4}$ interface. ACS Nano 4(5), 28112821 (2010)

27. Y. Chen, Z. Cai, Y. Kuru, W. Ma, H.L. Tuller, B. Yildiz, Electronic activation of cathode superlattices at elevated temperatures- source of markedly accelerated oxygen reduction kinetics. Adv. Energy Mater. 3, 1221-1229 (2013)

28. Y. Kuru, S.R. Bishop, J.J. Kim, B. Yildiz, H.L. Tuller, Chemomechanical properties and microstructural stability of nanocrystalline Pr-doped ceria: an in situ X-ray diffraction investigation. Solid State Ionics 193(1), 1-4 (2011) 
29. Y.-H. Kim, S.-I. Pyun, J.-Y. Go, An investigation of intercalation-induced stresses generated during lithium transport through sol-gel derived $\mathrm{Li}_{x} \mathrm{Mn}_{2} \mathrm{O}_{4}$ film electrode using a laser beam deflection method. Electrochim. Acta 51, 441449 (2005)

30. S.-I. Pyun, J.-Y. Go, T.-S. Jang, An investigation of intercalationinduced stresses generated during lithium transport through $\mathrm{Li}_{1-\delta} \mathrm{CoO}_{2}$ film electrode using a laser beam deflection method. Electrochim. Acta 49, 4477-4486 (2004)

31. V.A. Sethuraman, N. Van Winkle, D.P. Abraham, A.F. Bower, P.R. Guduru, Real-time stress measurements in lithium-ion battery negative-electrodes. J. Power Sources 206, 334-342 (2012)

32. Q. Yang, T.E. Burye, R.R. Lunt, J.D. Nicholas, In situ oxygen surface exchange coefficient measurements on lanthanum strontium ferrite thin films via the curvature relaxation method. Solid State Ionics 249-250, 123-128 (2013)

33. B.W. Sheldon, S. Mandowara, J. Rankin, Grain boundary induced compositional stress in nanocrystalline ceria films. Solid State Ionics 233, 38-46 (2013)

34. K. Nassau, The Physics and Chemistry of Color: The Fifteen Causes of Color (Wiley, New York, 1983)

35. R. Waser, T. Bieger, J. Maier, Determination of acceptor concentrations and energy levels in oxides using an optoelectrochemical technique. Solid State Commun. 76, 1077-1081 (1990)

36. T. Bieger, J. Maier, Kinetics of oxygen incorporation in $\mathrm{SrTiO}_{3}$ (Fe-doped): an optical investigation. Sensors and Actuators B 7, 763-768 (1992)

37. J.J. Kim, S.R. Bishop, N. Thompson, Y. Kuru, H.L. Tuller, Optically derived energy band gap states of Pr in ceria. Solid State Ionics 225, 198-200 (2012)

38. S.R. Bishop, J.J. Kim, N. Thompson, H.L. Tuller, Probing redox kinetics in Pr doped ceria mixed ionic electronic conducting thin films by in situ optical absorption measurements. ECS Trans. 45(1), 491-495 (2012)

39. P.R. Shearing, L.E. Howard, P.S. Jørgensen, N.P. Brandon, S.J. Harris, Characterization of the 3-dimensional microstructure of a graphite negative electrode from a Li-ion battery. Electrochem. Commun. 12(3), 374-377 (2010)

40. M. Ebner, F. Geldmacher, F. Marone, M. Stampanoni, V. Wood, $\mathrm{X}$-ray tomography of porous, transition metal oxide based lithium ion battery electrodes. Adv. Energy Mater. 3, 845-850 (2013)

41. J. Wang, Y.-c.K. Chen, Q. Yuan, A. Tkachuk, C. Erdonmez, B. Hornberger, M. Feser, Automated markerless full field hard Xray microscopic tomography at sub-50nm 3-dimension spatial resolution. Appl. Phys. Lett. 100(14), 143107 (2012)

42. J.R. Wilson, W. Kobsiriphat, R. Mendoza, H.-Y. Chen, J.M. Hiller, D.J. Miller, K. Thornton, P.W. Voorhees, S.B. Adler, S.A. Barnett, Three-dimensional reconstruction of a solid-oxide fuel-cell anode. Nat. Mater. 5(7), 541-544 (2006)

43. R. Clague, P.R. Shearing, P.D. Lee, Z. Zhang, D.J.L. Brett, A.J. Marquis, N.P. Brandon, Stress analysis of solid oxide fuel cell anode microstructure reconstructed from focused ion beam tomography. J. Power Sources. 196(21), 9018-9021 (2011)

44. J.R. Wilson, J.S. Cronin, S.A. Barnett, S.J. Harris, Measurement of three-dimensional microstructure in a $\mathrm{LiCoO}_{2}$ positive electrode. J. Power Sources 196(7), 3443-3447 (2011)

45. Z. Cai, Y. Kuru, J.W. Han, Y. Chen, B. Yildiz, Surface electronic structure transitions at high temperature on perovskite oxides: the case of strained $\mathrm{La}_{0.8} \mathrm{Sr}_{0.2} \mathrm{CoO}_{3}$ thin films. J. Am. Chem. Soc. 133(44), 17696-17704 (2011)

46. C. Zhang, M.E. Grass, A.H. McDaniel, S.C. DeCaluwe, F. El Gabaly, Z. Liu, K.F. McCarty, R.L. Farrow, M.A. Linne, Z. Hussain, G.S. Jackson, H. Bluhm, B.W. Eichhorn, Measuring fundamental properties in operating solid oxide electro- chemical cells by using in situ X-ray photoelectron spectroscopy. Nat. Mater. 9(11), 944-949 (2010)

47. E. Mutoro, E.J. Crumlin, H. Pöpke, B. Luerssen, M. Amati, M.K. Abyaneh, M.D. Biegalski, H.M. Christen, L. Gregoratti, J. Janek, Y. Shao-Horn, Reversible compositional control of oxide surfaces by electrochemical potentials. J. Phys. Chem. Lett. 3(1), 40-44 (2012)

48. S.V. Kalinin, N. Balke, Local electrochemical functionality in energy storage materials and devices by scanning probe microscopies: status and perspectives. Adv. Mater. 22(35), E193-E209 (2010)

49. J.W. Bullard III, R.L. Smith, Structural evolution of the $\mathrm{MoO}_{3}$ surface during lithium intercalation. Solid State Ionics 160, 335349 (2003)

50. J.W. Bullard III, R.L. Smith, In situ electrochemical scanning probe microscopy of lithium battery cathode materials: vanadium pentoxide $\left(\mathrm{V}_{2} \mathrm{O}_{5}\right)$. Mat. Res. Soc. Symp. Proc. 756, EE7.10.1EE7.10.6 (2003)

51. D.N. Leonard, A. Kumar, S. Jesse, M.D. Biegalski, H.M. Christen, E. Mutoro, E.J. Crumlin, Y. Shao-Horn, S.V. Kalinin, A.Y. Borisevich, Nanoscale probing of voltage activated oxygen reduction/evolution reactions in nanopatterned $\left(\mathrm{La}_{x} \mathrm{Sr}_{1-x}\right) \mathrm{CoO}_{3-\delta}$ cathodes. Adv. Energy Mater. 3, 788-797 (2013)

52. N. Balke, S. Jesse, A.N. Morozovska, E. Eliseev, D.W. Chung, Y. Kim, L. Adamczyk, R.E. García, N. Dudney, S.V. Kalinin, Nanoscale mapping of ion diffusion in a lithium-ion battery cathode. Nat. Nanotechnol. 5, 749-754 (2010)

53. H. Jalili, J.W. Han, Y. Kuru, Z. Cai, B. Yildiz, New insights into the strain coupling to surface chemistry, electronic structure, and reactivity of $\mathrm{La}_{0.7} \mathrm{Sr}_{0.3} \mathrm{MnO}_{3}$. J. Phys. Chem. Lett. 2(7), 801-807 (2011)

54. K. Katsiev, B. Yildiz, K. Balasubramaniam, P.A. Salvador, Electron tunneling characteristics on $\mathrm{La}_{0.7} \mathrm{Sr}_{0.3} \mathrm{MnO}_{3}$ thin-film surfaces at high temperature. Appl. Phys. Lett. 95(9), 092106 (2009)

55. Y. Chen, W. Jung, Z. Cai, J.J. Kim, H.L. Tuller, B. Yildiz, Impact of $\mathrm{Sr}$ segregation on the electronic structure and oxygen reduction activity of $\mathrm{SrTi}_{1-x} \mathrm{Fe}_{x} \mathrm{O}_{3}$ surfaces. Energy Environ. Sci. 5(7), 7979-7988 (2012)

56. J. Zapata, M. Burriel, P. García, J.A. Kilner, J. Santiso, Anisotropic ${ }^{18} \mathrm{O}$ tracer diffusion in epitaxial films of $\mathrm{GdBaCo}$ ${ }_{2} \mathrm{O}_{5+\delta}$ cathode material with different orientations. J. Mater. Chem. A 1, 7408-7414 (2013)

57. M. Burriel, G. Garcia, J. Santiso, J.A. Kilner, R.J. Chater, S.J. Skinner, Anisotropic oxygen diffusion properties in epitaxial thin films of $\mathrm{La}_{2} \mathrm{NiO}_{4+\delta}$. J. Mater. Chem. 18, 416-422 (2008)

58. M. Abazari, M. Tsuchiya, S. Ramanathan, High-temperature electrical conductivity measurements on nanostructured yttriadoped ceria thin films in ozone. J. Am. Ceram. Soc. 95(1), 312317 (2012)

59. D. Chen, S.R. Bishop, H.L. Tuller, Praseodymium-cerium oxide thin film cathodes: Study of oxygen reduction reaction kinetics. J. Electroceram. 28(1), 62-69 (2012)

60. W. Lai, S.M. Haile, Impedance spectroscopy as a tool for chemical and electrochemical analysis of mixed conductors: a case study of ceria. J. Am. Ceram. Soc. 88(11), 29792997 (2005)

61. D. Aurbach, B. Markovsky, A. Rodkin, E. Levi, Y.S. Cohen, H.-J. Kim, M. Schmidt, On the capacity fading of $\mathrm{LiCoO}_{2}$ intercalation electrodes: the effect of cycling, storage, temperature, and surface film forming additives. Electrochim. Acta 47, 4291-4306 (2002)

62. E. Barsoukov, J.H. Kim, J.H. Kim, C.O. Yoon, H. Lee, Kinetics of lithium intercalation into carbon anodes: in situ impedance 
investigation of thickness and potential dependence. Solid State Ionics 116, 249-261 (1999)

63. I. Uchida, H. Ishikawa, M. Mohamedi, M. Umeda, ACimpedance measurements during thermal runaway process in several lithium/polymer batteries. J. Power Sources. 119-121, 821-825 (2003)

64. F.S. Baumann, J. Fleig, G. Cristiani, B. Stuhlhofer, H.-U. Habermeier, J. Maier, Quantitative comparison of mixed conducting SOFC cathode materials by means of thin film model electrodes. J. Electrochem. Soc. 154(9), B931-B941 (2007)

65. J. Fleig, H.-R. Kim, J. Jamnik, J. Maier, Oxygen reduction kinetics of lanthanum manganite (LSM) model cathodes: partial pressure dependence and rate-limiting steps. Fuel Cells. 8(5), 330-337 (2008)

66. W.C. Chueh, S.M. Haile, Electrochemical studies of capacitance in cerium oxide thin films and its relationship to anionic and electronic defect densities. Phys. Chem. Chem. Phys. 11, 8144-8148 (2009)

67. H. Wang, Y.-I. Jang, B. Huang, D.R. Sadoway, Y.-M. Chiang, TEM study of electrochemical cycling-induced damage and disorder in $\mathrm{LiCoO}_{2}$ cathodes for rechargeable lithium batteries. J. Electrochem. Soc. 146(2), 473-480 (1999)

68. D. Miller, C. Proff, J. Wen, D. Abraham, Direct observation of microstructural evolution in Li battery cathode oxide particles during electrochemical cycling by in situ electron microscopy. Microsc. Microanal. 18(S2), 1108-1109 (2012)

69. S.J. Harris, A. Timmons, D.R. Baker, C. Monroe, Direct in situ measurements of $\mathrm{Li}$ transport in Li-ion battery negative electrodes. Chem. Phys. Lett. 485, 265-274 (2010)

70. Y. Qi, S.J. Harris, In situ observation of strains during lithiation of a graphite electrode. J. Electrochem. Soc. 157(6), A741-A747 (2010)

71. C.M. Wang, W. Xu, J. Liu, D.W. Choi, B. Arey, L.V. Saraf, J.G. Zhang, Z.G. Yang, S. Thevuthasan, D.R. Baer, N. Salmon, In situ transmission electron microscopy and spectroscopy studies of interfaces in $\mathrm{Li}$ ion batteries: challenges and opportunities. J. Mater. Res. 25(8), 1541-1547 (2010)

72. J.Y. Huang, L. Zhong, C.M. Wang, J.P. Sullivan, W. Xu, L.Q. Zhang, S.X. Mao, N.S. Hudak, X.H. Liu, A. Subramanian, H. Fan, L. Qi, A. Kushima, J. Li, In situ observation of the electrochemical lithiation of a single $\mathrm{SnO}_{2}$ nanowire electrode. Science. 330(6010), 1515-1520 (2010)

73. J. Rankin, L.W. Hobbs, L.A. Boatner, C.W. White, An in situ annealing study of lead implanted single crystal calcium titanate. Nucl. Inst. Methods Phys. Res. B 32, 28-31 (1988)

74. C. Villevieille, M. Boinet, L. Monconduit, Direct evidence of morphological changes in conversion type electrodes in Li-ion battery by acoustic emission. Electrochem. Commun. 12(10), 1336-1339 (2010)

75. K. Rhodes, N. Dudney, E. Lara-Curzio, C. Daniel, Understanding the degradation of silicon electrodes for lithium-ion batteries using acoustic emission. J. Electrochem. Soc. 157(12), A1354A1360 (2010)

76. T. Ohzuku, H. Tomura, K. Sawai, Monitoring of particle fracture by acoustic emission during charge and discharge of $\mathrm{Li} / \mathrm{MnO} 2$ cells. J. Electrochem. Soc. 144(10):3496-3500 (1997)

77. K. Sawai, H. Tomura, T. Ohzuku, Acoustic emission histometry for battery material research. Denki Kagaku 66(3):301-307 (1998)

78. K. Sawai, K. Yoshikawa, H. Tomura, T. Ohzuku, Characterization of materials by acoustic emission histometry for advanced lithium batteries. Prog. Batter. Battery Mater. 17, 201-207 (1998)

79. S. Didier-Laurent, H. Idrissi, L. Roué, In-situ study of the cracking of metal hydride electrodes by acoustic emission technique. J. Power Sources 179(1), 412-416 (2008)
80. Y. Kimura, T. Kushi, S.-i. Hashimoto, K. Amezawa, T. Kawada, Influences of temperature and oxygen partial pressure on mechanical properties of $\mathrm{La}_{0.6} \mathrm{Sr}_{0.4} \mathrm{Co}_{1-y} \mathrm{Fe}_{y} \mathrm{O}_{3-\delta}$. J. Am. Ceram. Soc. 95(8), 2608-2613 (2012)

81. K. Amezawa, T. Kushi, K. Sato, A. Unemoto, S.-i. Hashimoto, T. Kawada, Elastic moduli of $\mathrm{Ce}_{0.9} \mathrm{Gd}_{0.1} \mathrm{O}_{2-\delta}$ at high temperatures under controlled atmospheres. Solid State Ionics 198(1), 32-38 (2011)

82. T. Kushi, K. Sato, A. Unemoto, S. Hashimoto, K. Amezawa, T. Kawada, Elastic modulus and internal friction of SOFC electrolytes at high temperatures under controlled atmospheres. J. Power Sources 196(19), 7989-7993 (2011)

83. K. Sato, K. Yashiro, T. Kawada, H. Yugami, T. Hashida, J. Mizusaki, Fracture process of nonstoichiometric oxide based solid oxide fuel cell under oxidizing/reducing gradient conditions. J. Power Sources 195(17), 5481-5486 (2010)

84. S. Watanabe, K. Sato, Y. Takeyama, F. Iguchi, K. Yashiro, T. Hashida, J. Mizusaki, T. Kawada, in Proceedings of the ASME 2010 Eighth International Fuel Cell Science, Engineering and Technology Conference. Development of in-situ mechanical testing method for SOFC components (2010)

85. J. Milhans, D.S. Li, M. Khaleel, X. Sun, M.S. Al-Haik, A. Harris, H. Garmestani, Mechanical properties of solid oxide fuel cell glass-ceramic seal at high temperatures. J. Power Sources 196(13), 5599-5603 (2011)

86. M. Qu, W.H. Woodford, J.M. Maloney, W. Craig Carter, Y.-M. Chiang, K.J. Van Vliet, Nanomechanical quantification of elastic, plastic, and fracture properties of $\mathrm{LiCoO}_{2}$. Adv. Energy Mater. 2(8), 940-944 (2012)

87. T. Maxisch, G. Ceder, Elastic properties of olivine $\mathrm{Li}_{x} \mathrm{FePO}_{4}$ from first principles. Phys. Rev. B. 73, 174112 (2006)

88. Y. Qi, H. Guo, L.G. Hector Jr., A. Timmons, Threefold increase in the Young's modulus of graphite negative electrode during lithium intercalation. J. Electrochem. Soc. 157(5), A558-A566 (2010)

89. V. Kanchana, G. Vaitheeswaran, A. Svane, A. Delin, Firstprinciples study of elastic properties of $\mathrm{CeO}_{2}, \mathrm{ThO}_{2}$ and $\mathrm{PoO}_{2}$. J. Phys. Condens. Matter 18(42), 9615-9624 (2006)

90. A. Kushima, B. Yildiz, Oxygen ion diffusivity in strained yttria stabilized zirconia: where is the fastest strain? J. Mater. Chem. 20(23), 4809 (2010)

91. S. Shi, Y. Qi, H. Li, L.G. Hector Jr., Defect thermodynamics and diffusion mechanisms in $\mathrm{Li}_{2} \mathrm{CO}_{3}$ and implications for the solid electrolyte interphase in li-ion batteries. J. Phys. Chem. 117, 8579-8593 (2013)

92. D. Marrocchelli, S.R. Bishop, H.L. Tuller, G.W. Watson, B. Yildiz, Charge localization increases chemical expansion in cerium-based oxides. Phys. Chem. Chem. Phys. 14(35), 12070 (2012)

93. P.P. Dholabhai, S. Anwar, J.B. Adams, P. Crozier, R. Sharma, Kinetic lattice Monte Carlo model for oxygen vacancy diffusion in praseodymium doped ceria: applications to materials design. J. Solid State Chem. 184(4), 811-817 (2011)

94. P.P. Dholabhai, J.B. Adams, P. Crozier, R. Sharma, Oxygen vacancy migration in ceria and $\mathrm{Pr}$-doped ceria: A DFT+U study. J. Chem. Phys. 132(9), 094104 (2010)

95. Y.-T. Cheng, M.W. Verbrugge, The influence of surface mechanics on diffusion induced stresses within spherical nanoparticles. J. Appl. Phys. 104, 083521 (2008)

96. Y.-T. Cheng, M.W. Verbrugge, Evolution of stress within a spherical insertion electrode particle under potentiostatic and galvanostatic operation. J. Power Sources 190, 453-460 (2009)

97. Y.-T. Cheng, M.W. Verbrugge, Diffusion-induced stress, interfacial charge transfer, and criteria for avoiding crack initiation 
of electrode particles. J. Electrochem. Soc. 157(4), A508-A516 (2010)

98. R. Deshpande, Y.-T. Cheng, M.W. Verbrugge, A. Timmons, Diffusion induced stresses and strain energy in a phase-transforming spherical electrode particle. J. Electrochem. Soc. 158(6), A718A724 (2011)

99. J. Christensen, J. Newman, A mathematical model of stress generation and fracture in lithium manganese oxide. J. Electrochem. Soc. 153(6), A1019-A1030 (2006)

100. J. Park, W. Lu, A.M. Sastry, Numerical simulation of stress evolution in lithium manganese dioxide particles due to coupled phase transition and intercalation. J. Electrochem. Soc. 158(2), A201-A206 (2011)

101. X. Zhang, W. Shyy, A.M. Sastry, Numerical simulation of intercalation-induced stress in Li-ion battery electrode particles. J. Electrochem. Soc. 154(10), A910-A916 (2007)

102. X. Zhang, A.M. Sastry, W. Shyy, Intercalation-induced stress and heat generation within single lithium-ion battery cathode particles. J. Electrochem. Soc. 155(7), A542-A552 (2008)

103. R. Deshpande, Y. Qi, Y.-T. Cheng, Effects of concentrationdependent elastic modulus on diffusion-induced stresses for battery applications. J. Electrochem. Soc. 157(8), A967-A971 (2010)

104. S.J. Harris, R.D. Deshpande, Y. Qi, I. Dutta, Y.-T. Cheng, Mesopores inside electrode particles can change the $\mathrm{Li}$-ion transport mechanism and diffusion-induced stress. J. Mater. Res. 25(8), 1433-1440 (2010)

105. K.E. Aifantis, J.P. Dempsey, Stable crack growth in nanostructured Li-batteries. J. Power Sources 143, 203-211 (2005)

106. K.E. Aifantis, S.A. Hackney, J.P. Dempsey, Design criteria for nanostructured Li-ion batteries. J. Power Sources 165, 874-879 (2007)

107. Y. Hu, X. Zhao, Z. Suo, Averting cracks caused by insertion reaction in lithium-ion batteries. J. Mater. Res. 25(6), 1007-1010 (2010)

108. M. Doyle, J.C. Newman, Analysis of capacity-rate data for lithium batteries using simplified models of the discharge process. J. Appl. Electrochem. 27, 846-856 (1997)

109. M. Doyle, J. Newman, A.S. Gozdz, C.N. Schmutz, J.-M. Tarascon, Comparison of modeling predictions with experimental data from plastic lithium ion cells. J. Electrochem. Soc. 143(6), 1890-1903 (1996)

110. M. Doyle, T.F. Fuller, J. Newman, Modeling of galvanostatic charge and discharge of the lithium/polymer/insertion cell. J. Electrochem. Soc. 140(6), 1526-1533 (1993)

111. M. Doyle, J. Newman, The use of mathematical modeling in the design of lithium/polymer battery systems. Electrochim. Acta 40, 2191-2196 (1995)

112. J. Newman, W. Tiedemann, Porous-electrode theory with battery applications. Aiche J. 21(1), 25-41 (1975)

113. T.F. Fuller, M. Doyle, J. Newman, Simulation and optimization of the dual lithium ion insertion cell. J. Electrochem. Soc. 141(1), $1-10$ (1994)

114. S. Golmon, K. Maute, M.L. Dunn, Numerical modeling of electrochemical-mechanical interactions in lithium polymer batteries. Comput. Struct. 87, 1567-1579 (2009)

115. S. Renganathan, G. Sikha, S. Santhanagopalan, R.E. White, Theoretical analysis of stresses in a lithium ion cell. J. Electrochem. Soc. 157(2), A155-A163 (2010)

116. J. Christensen, Modeling diffusion-induced stress in Li-ion cells with porous electrodes. J. Electrochem. Soc. 157(3), A366-A380 (2010)

117. R. Purkayastha, R.M. McMeeking, A linearized model for lithium ion batteries and maps for their performance and failure. J. Appl. Mech. 79(3), 031021 (2012)
118. R.T. Purkayastha, R.M. McMeeking, An integrated 2-D model of a lithium ion battery: the effect of material parameters and morphology on storage particle stress. Comput. Mech. 50(2), 209-227 (2012)

119. J. Christensen, J. Newman, Stress generation and fracture in lithium insertion materials. J. Sold State Electrochem. 10, 293 319 (2006)

120. R.E. García, Y.-M. Chiang, W.C. Carter, P. Limthongkul, C.M. Bishop, Microstructrual modeling and design of rechargeable lithium-ion batteries. J. Electrochem. Soc. 152(1), A255-A263 (2005)

121. M. Smith, R.E. García, Q.C. Horn, The effect of microstructure on the galvanostatic discharge of graphite anode electrodes in $\mathrm{LiCoO}_{2}$-based rocking-chair rechargeable batteries. J. Electrochem. Soc. 156(11), A896-A904 (2009)

122. M.D. Chung, J.H. Seo, X.C. Zhang, A.M. Sastry, Implementing realistic geometry and measured diffusion coefficients into single particle electrode modeling based on experiments with single $\mathrm{LiMn}_{2} \mathrm{O}_{4}$ spinel particles. J. Electrochem. Soc. 158(4), A371A378 (2011)

123. H.-W. Chiang, R.N. Blumenthal, R.A. Fournelle, A high temperature lattice parameter and dilatometer study of the defect structure of nonstoichiometric cerium dioxide. Solid State Ionics 66, 85-95 (1993)

124. S.R. Bishop, K. Duncan, E.D. Wachsman, Thermo-chemical expansion of SOFC materials. ECS Trans. 1, 13-21 (2006)

125. C.Y. Park, A.J. Jacobson, Thermal and chemical expansion properties of $\mathrm{La}_{0.2} \mathrm{Sr}_{0.8} \mathrm{Fe}_{0.55} \mathrm{Ti}_{0.45} \mathrm{O}_{3-x}$. Solid State Ionics 176(3536), 2671-2676 (2005)

126. S.B. Adler, Chemical expansivity of electrochemical ceramics. J. Am. Ceram. Soc. 84, 2117-2119 (2001)

127. S.J. Hong, A.V. Virkar, Lattice parameters and densities of rareearth oxide doped ceria electrolytes. J. Am. Ceram. Soc. 78(2), 433-439 (1995)

128. S.R. Bishop, K.L. Duncan, E.D. Wachsman, Thermo-chemical expansion in strontium-doped lanthanum cobalt iron oxide. J. Am. Ceram. Soc. 93(12), 4115-4121 (2010)

129. S.R. Bishop, J.-J. Kim, N. Thompson, D. Chen, Y. Kuru, T. Stefanik, H.L. Tuller, Mechanical, electrical, and optical properties of $(\mathrm{Pr}, \mathrm{Ce}) \mathrm{O}_{2}$ solid solutions: kinetic studies. ECS Trans. 35, 1137-1144 (2011)

130. S.R. Bishop, H.L. Tuller, Development of a predictive thermochemical expansion and stress model in $(\mathrm{Pr}, \mathrm{Ce}) \mathrm{O}_{2-\delta}$. ECS Trans. 41, 153-159 (2012)

131. M. Morales, J.J. Roa, X.G. Capdevila, M. Segarra, S. Piñol, Mechanical properties at the nanometer scale of GDC and YSZ used as electrolytes for solid oxide fuel cells. Acta Mater. 58(7), 2504-2509 (2010)

132. R. Korobko, C.-T. Chen, S. Kim, S.R. Cohen, E. Wachtel, N. Yavo, I. Lubomirsky, Influence of Gd content on the room temperature mechanical properties of Gd-doped ceria. Scripta Mater. 66(3-4), 155-158 (2012)

133. E. Wachtel, I. Lubomirsky, The elastic modulus of pure and doped ceria. Scripta Mater. 65(2), 112-117 (2011)

134. N.I. Karageorgakis, A. Heel, J.L.M. Rupp, M.H. Aguirre, T. Graule, L.J. Gauckler, Properties of flame sprayed $\mathrm{Ce}_{0.8} \mathrm{Gd}_{0.2} \mathrm{O}_{1.9-\delta}$ electrolyte thin films. Adv. Funct. Mater. 21(3), 532-539 (2011)

135. Y. Wang, K. Duncan, E.D. Wachsman, F. Ebrahimi, The effect of oxygen vacancy concentration on the elastic modulus of fluorite-structured oxides. Solid State Ionics 178(1-2), 5358 (2007)

136. T. Hashida, K. Sato, Y. Takeyama, T. Kawada, J. Mizusaki, Deformation and fracture characteristics of zirconia and ceriabased electrolytes for SOFCs under reducing atmospheres. ECS Trans. 25, 1565-1572 (2009) 
137. A. Atkinson, A. Selçuk, Mechanical behaviour of ceramic oxygen ion-conducting membranes. Solid State Ionics 134, 59-66 (2000)

138. A. Atkinson, T.M.G.M. Ramos, Chemically-induced stresses in ceramic oxygen ion-conducting membranes. Solid State Ionics 129, 259-269 (2000)

139. R. Krishnamurthy, B.W. Sheldon, Stresses due to oxygen potential gradients in non-stoichiometric oxides. Acta Mater. 52, 1807-1822 (2004)

140. S. Sinha, D.W. Murphy, Lithium intercalation in cubic $\mathrm{TiS}_{2}$. Solid State Ionics 20(1), 81-84 (1986)

141. A. Yamada, H. Koizumi, N. Sonoyama, R. Kanno, Phase change in $\mathrm{Li}_{x} \mathrm{FePO}_{4}$. Electrochem. Solid-State Lett. 8(8), A409-A413 (2005)

142. T. Ohzuku, M. Kitagawa, T. Hirai, Electrochemistry of manganese dioxide in lithium nonaqueous cell III. X-ray diffractional study on the reduction of spinel-related manganese dioxide. J. Electrochem. Soc. 137(3), 769-775 (1990)

143. J.N. Reimers, J.R. Dahn, Electrochemical and in situ X-ray diffraction studies of lithium intercalation in $\mathrm{Li}_{x} \mathrm{CoO}_{2}$. J. Electrochem. Soc. 139(8), 2091 (1992)

144. Y.-I. Jang, B. Huang, H. Wang, D.R. Sadoway, G. Ceder, Y.-M. Chiang, H. Liu, H. Tamura, $\mathrm{LiAl}_{y} \mathrm{Co}_{1-y} \mathrm{O}_{2}(\mathrm{R} \overline{3} \mathrm{~m})$ intercalation cathode for rechargeable lithium batteries. J. Electrochem. Soc. 146(3), 862-868 (1999)

145. H. Wang, Y.-I. Jang, B. Huang, D.R. Sadoway, Y.-M. Chiang, Electron microscopic characterization of electrochemically cycled $\mathrm{LiCoO}_{2}$ and $\mathrm{Li}(\mathrm{Al}, \mathrm{Co}) \mathrm{O}_{2}$ battery cathodes. J. Power Sources 81-82, 594-598 (1999)

146. H. Gabrisch, J. Wilcox, M.M. Doeff, TEM study of fracturing in spherical and plate-like $\mathrm{LiFePO}_{4}$ particles. Electrochem. SolidState Lett. 11(3), A25-A29 (2008)

147. J. Shim, R. Kostecki, T. Richardson, X. Song, K.A. Striebel, Electrochemical analysis for cycle performance and capacity fading of a lithium-ion battery cycled at elevated temperature. J. Power Sources 112(1), 222-230 (2002)

148. Y. Shin, A. Manthiram, Factors influencing the capacity fade of spinel lithium manganese oxides. J. Electrochem. Soc. 151(2), A204-A208 (2004)

149. Y. Itou, Y. Ukyo, Performance of $\mathrm{LiNiCoO}_{2}$ materials for advanced lithium-ion batteries. J. Power Sources 146(1-2), 3944 (2005)

150. M. Kerlau, J.A. Reimer, E.J. Cairns, Investigation of particle isolation in Li-ion battery electrodes using ${ }^{7} \mathrm{Li}$ NMR spectroscopy. Electrochem. Commun. 7(12), 1249-1251 (2005)

151. W. Choi, A. Manthiram, Superior capacity retention spinel oxyfluoride cathodes for lithium-ion batteries. Electrochem. Solid-State Lett. 9(5), A245-A248 (2006)

152. Q.C. Horn, K. White, in 211th Meeting of The Electrochemical Society. Understanding lithium-ion degradation and failure mechanisms by cross-section analysis (2007)

153. S. Bhattacharya, A.R. Riahi, A.T. Alpas, In-situ observations of lithiation/de-lithiation induced graphite damage during electrochemical cycling. Scripta Mater. 64(2), 165-168 (2011)

154. B.X. Huang, V. Vasechko, Q.L. Ma, J. Malzbender, Thermomechanical properties of $(\mathrm{Sr}, \mathrm{Y}) \mathrm{TiO}_{3}$ as anode material for solid oxide fuel cells. J. Power Sources 206, 204-209 (2012)

155. S. Giraud, J. Canel, Young's modulus of some SOFCs materials as a function of temperature. J. Eur. Ceram. Soc. 28(1), 77-83 (2008)

156. M. Mavrikakis, B. Hammer, J. Nørskov, Effect of strain on the reactivity of metal surfaces. Phys. Rev. Lett. 81(13), 2819-2822 (1998)

157. B. Hammer, J.K. Nørskov, Why gold is the noblest of all the metals. Nature. 376, 238-240 (1995)
158. F.W. Herbert, K.J. Van Vliet, B. Yildiz, Plasticity-induced oxidation reactivity on $\mathrm{Ni}(100)$ studied by scanning tunneling spectroscopy. MRS Commun. 2(01), 23-27 (2012)

159. P. Strasser, S. Koh, T. Anniyev, J. Greeley, K. More, C. Yu, Z. Liu, S. Kaya, D. Nordlund, H. Ogasawara, M.F. Toney, A. Nilsson, Lattice-strain control of the activity in dealloyed core-shell fuel cell catalysts. Nat. Chem. 2(6), 454-460 (2010)

160. J. Suntivich, H.A. Gasteiger, N. Yabuuchi, H. Nakanishi, J.B. Goodenough, Y. Shao-Horn, Design principles for oxygenreduction activity on perovskite oxide catalysts for fuel cells and metal-air batteries. Nat. Chem. 3(7), 546-550 (2011)

161. Y.-L. Lee, J. Kleis, J. Rossmeisl, Y. Shao-Horn, D. Morgan, Prediction of solid oxide fuel cell cathode activity with firstprinciples descriptors. Energy Environ. Sci. 4, 3966-3970 (2011)

162. W. Jung, H.L. Tuller, A new model describing solid oxide fuel cell cathode kinetics: model thin film $\mathrm{SrTi}_{1-x} \mathrm{Fe}_{x} \mathrm{O}_{3-\delta}$ mixed conducting oxides-a case study. Adv. Energy Mater. 1(6), 1184 1191 (2011)

163. A. Chroneos, B. Yildiz, A. Tarancón, D. Parfitt, J.A. Kilner, Oxygen diffusion in solid oxide fuel cell cathode and electrolyte materials: mechanistic insights from atomistic simulations. Energy Environ. Sci. 4(8), 2774-2789 (2011)

164. J.W. Han, B. Yildiz, Enhanced one dimensional mobility of oxygen on strained $\mathrm{LaCoO}_{3}(001)$ surface. J. Mater. Chem. 21(47), 18983 (2011)

165. A. Kushima, S. Yip, B. Yildiz, Competing strain effects in reactivity of $\mathrm{LaCoO}_{3}$ with oxygen. Phys. Rev. B 82(11), 115435 (2010)

166. A. Lussier, J. Dvorak, S. Stadler, J. Holroyd, M. Liberati, E. Arenholz, S.B. Ogale, T. Wu, T. Venkatesan, Y.U. Idzerda, Stress relaxation of $\mathrm{La}_{1 / 2} \mathrm{Sr}_{1 / 2} \mathrm{MnO}_{3}$ and $\mathrm{La}_{2 / 3} \mathrm{Ca}_{1 / 3} \mathrm{MnO}_{3}$ at solid oxide fuel cell interfaces. Thin Solid Films 516(6), 880-884 (2008)

167. H. Yamada, M. Kawasaki, Y. Tokura, Epitaxial growth and valence control of strained perovskite $\mathrm{SrFeO}_{3}$ films. Appl. Phys. Lett. 80, 622-624 (2002)

168. G. Jose la O', S.-J. Ahn, E. Crumlin, Y. Orikasa, M.D. Biegalski, H.M. Christen, Y. Shao-Horn, Catalytic activity enhancement for oxygen reduction on epitaxial perovskite thin films for solidoxide fuel cells. Angew. Chem. Int. Ed. 49(31), 5344-5347 (2010)

169. K. Szot, M. Pawelczyk, J. Herion, C.h. Freiburg, J. Albers, R. Waser, J. Hulliger, J. Kwapulinski, J. Dec, Nature of the surface layer in $\mathrm{ABO}_{3}$-type perovskites at elevated temperatures. Appl. Phys. A 62, 335-343 (1996)

170. T.T. Fister, D.D. Fong, J.A. Eastman, P.M. Baldo, M.J. Highland, P.H. Fuoss, K.R. Balasubramaniam, J.C. Meador, P.A. Salvador, In situ characterization of strontium surface segregation in epitaxial $\mathrm{La}_{0.7} \mathrm{Sr}_{0.3} \mathrm{MnO}_{3}$ thin films as a function of oxygen partial pressure. Appl. Phys. Lett. 93(15), 151904 (2008)

171. C.N. Borca, B. Xu, T. Komesu, H.-K. Jeong, M.T. Liu, S.H. Liou, P.A. Dowben, The surface phases of the $\mathrm{La}_{0.65} \mathrm{~Pb}_{0.35} \mathrm{MnO}_{3}$ manganese perovskite surface. Surf. Sci. 512, L346-L352 (2002)

172. H. Dulli, E.W. Plummer, P.A. Dowben, J. Choi, S.-H. Liou, Surface electronic phase transition in colossal magnetoresistive manganese perovskites: $\mathrm{La}_{0.65} \mathrm{Sr}_{0.35} \mathrm{MnO}_{3}$. Appl. Phys. Lett. 77(4), 570-572 (2000)

173. W. Jung, H.L. Tuller, Investigation of surface $\mathrm{Sr}$ segregation in model thin film solid oxide fuel cell perovskite electrodes. Energy Environ. Sci. 5, 5370-5378 (2012)

174. Z. Cai, M. Kubicek, J. Fleig, B. Yildiz, Chemical heterogeneities on $\mathrm{La}_{0.6} \mathrm{Sr}_{0.4} \mathrm{CoO}_{3-\delta}$ thin films-correlations to cathode surface activity and stability. Chem. Mater. 24(6), 1116-1127 (2012) 
175. M. Kubicek, A. Limbeck, T. Frömling, H. Hutter, J. Fleig, Relationship between cation segregation and the electrochemical oxygen reduction kinetics of $\mathrm{La}_{0.6} \mathrm{Sr}_{0.4} \mathrm{CoO}_{3-\delta}$ thin film electrodes. J. Electrochem. Soc. 158(6), B727-B734 (2011)

176. S.P. Jiang, J.G. Love, Origin of the initial polarization behavior of $\mathrm{Sr}$-doped $\mathrm{LaMnO}_{3}$ for $\mathrm{O}_{2}$ reduction in solid oxide fuel cells. Solid State Ionics 138, 183-190 (2001)

177. W. Lee, J.W. Han, Y. Chen, Z. Cai, B. Yildiz, Cation size mismatch and charge interactions drive dopant segregation at the surfaces of manganite perovskites. J. Am. Chem. Soc. 135, 7909-7925 (2013)

178. V.A. Sethuraman, V. Srinivasan, A.F. Bower, P.R. Guduru, In situ measurements of stress-potential coupling in lithiated silicon. J. Electrochem. Soc. 157(11), A1253-A1261 (2010)

179. A.K. Pannikkat, R. Raj, Measurement of an electrical potential induced by normal stress applied to the interface of an ionic material at elevated temperatures. Acta Mater. 47(12), 3423-3431 (1999)

180. A.F. Bower, P.R. Guduru, V.A. Sethuraman, A finite strain model of stress, diffusion, plastic flow, and electrochemical reactions in a lithium-ion half-cell. J. Mech. Phys. Solids 59(4), 804-828 (2011)

181. R.A. De Souza, A. Ramadan, S. Hörner, Modifying the barriers for oxygen-vacancy migration in fluorite-structured $\mathrm{CeO}_{2}$ electrolytes through strain: a computer simulation study. Energy Environ. Sci. 5, 5445-5453 (2012)

182. N. Sata, K. Eberman, K. Eberl, J. Maier, Mesoscopic fast ion conduction in nanometre-scale planar heterostructures. Nature. 408, 946-949 (2000)

183. I. Kosacki, C.M. Rouleau, P.F. Becher, J. Bentley, D.H. Lowndes, Nanoscale effects on the ionic conductivity in highly textured YSZ thin films. Solid State Ionics 176(13-14), 1319-1326 (2005)

184. J. Garcia-Barriocanal, A. Rivera-Calzada, M. Varela, Z. Sefrioui, E. Iborra, C. Leon, S.J. Pennycook, J. Santamaria, Colossal ionic conductivity at interfaces of epitaxial $\mathrm{ZrO}_{2}: \mathrm{Y}_{2} \mathrm{O}_{3} / \mathrm{SrTiO}_{3}$ heterostructures. Science 321(5889), 676-680 (2008)

185. X. Guo, Comment on Colossal Ionic Conductivity at Interfaces of Epitaxial $\mathrm{ZrO}_{2}: \mathrm{Y}_{2} \mathrm{O}_{3} / \mathrm{SrTiO}_{3}$ Heterostructures. Science 324(5926), 465 (2009)

186. A. Cavallaro, M. Burriel, J. Roqueta, A. Apostolidis, A. Bernardi, A. Tarancón, R. Srinivasan, S.N. Cook, H.L. Fraser, J.A. Kilner, D.W. McComb, J. Santiso, Electronic nature of the enhanced conductivity in YSZ-STO multilayers deposited by PLD. Solid State Ionics 181(13-14), 592-601 (2010)

187. N. Schichtel, C. Korte, D. Hesse, J. Janek, Elastic strain at interfaces and its influence on ionic conductivity in nanoscaled solid electrolyte thin films - theoretical considerations and experimental studies. Phys. Chem. Chem. Phys. 11(17), 3043 (2009)

188. H. Aydin, C. Korte, M. Rohnke, J. Janek, Oxygen tracer diffusion along interfaces of strained $\mathrm{Y}_{2} \mathrm{O}_{3} / \mathrm{YSZ}$ multilayers. Phys. Chem. Chem. Phys. 15, 1944-1955 (2013)

189. D. Pergolesi, E. Fabbri, S.N. Cook, V. Roddatis, E. Traversa, J.A. Kilner, Tensile lattice distortion does not affect oxygen transport in yttria-stabilized zirconia- $\mathrm{CeO}_{2}$ heterointerfaces. ACS Nano 6 , 10524-10534 (2012)

190. T.X.T. Sayle, S.C. Parker, D.C. Sayle, Ionic conductivity in nanoscale $\mathrm{CeO}_{2}$ /YSZ heterolayers. J. Mater. Chem. 16, 1067-1081 (2006)

191. B. Li, J. Zhang, T. Kaspar, V. Shutthanandan, R.C. Ewing, J. Lian, Multilayered YSZ/GZO films with greatly enhanced ionic conduction for low temperature solid oxide fuel cells. Phys. Chem. Chem. Phys. 15, 1296-1301 (2013)

192. S. Kim, H.J. Avila-Paredes, S. Wang, C.-T. Chen, R.A. De Souza, M. Martin, Z.A. Munir, On the conduction pathway for protons in nanocrystalline yttria-stabilized zirconia. Phys. Chem. Chem. Phys. 11, 3035-3038 (2009)

193. S. Sanna, V. Esposito, A. Tebano, S. Licoccia, E. Traversa, G. Balestrino, Enhancement of ionic conductivity in Sm-doped ceria/yttria-stabilized zirconia heteroepitaxial structures. Small 6(17), 1863-1867 (2010)

194. C. Korte, A. Peters, J. Janek, D. Hesse, N. Zakharov, Ionic conductivity and activation energy for oxygen ion transport in superlattices- the semicoherent multilayer system YSZ $\left(\mathrm{ZrO}_{2}+\right.$ $\left.9.5 \mathrm{~mol} \% \mathrm{Y}_{2} \mathrm{O}_{3}\right) / \mathrm{Y}_{2} \mathrm{O}_{3}$. Phys. Chem. Chem. Phys. 10, 4623 4635 (2008)

195. M. Sillassen, P. Eklund, N. Pryds, E. Johnson, U. Helmersson, J. Bøttiger, Low-temperature superionic conductivity in strained yttria-stabilized zirconia. Adv. Funct. Mater. 20(13), 2071-2076 (2010)

196. K. Mohan Kant, V. Esposito, N. Pryds, Strain induced ionic conductivity enhancement in epitaxial $\mathrm{Ce}_{0.9} \mathrm{Gd}_{0.1} \mathrm{O}_{2-\delta}$ thin films. Appl. Phys. Lett. 100(3), 033105 (2012)

197. Y.-M. Choi, S.-I. Pyun, Effects of intercalation-induced stress on lithium transport through porous $\mathrm{LiCoO}_{2}$ electrode. Solid State Ionics 99, 173-183 (1997) 